\title{
Unemployment dynamics and the Beveridge curve in Greece
}

Athanasios O. Tagkalakis

Correspondence:

atagkalakis@bankofgreece.gr Economic Analysis and Research

Department, Bank of Greece, El.

Venizelos 21, 10250 Athens, Greece

\begin{abstract}
In this paper, we investigate the unemployment dynamics and the determinants of the Beveridge curve in Greece. The economic recession alongside labor market reforms raised the inflow rate to and decreased the outflow rate from unemployment in the early crisis years. The gradual normalization of economic conditions and the adoption of further structural reforms led to a decline in the inflow rate and an increase in the outflow rate. Our results are suggestive of the presence of an inverse relationship between unemployment and vacancies in Greece, which is driven by the post-crisis developments.

JEL Classification: J63, E32, J64, O52

Keywords: Unemployment, Inflow, Outflows, Beveridge, Reforms
\end{abstract}

\section{Introduction}

The high and persistent unemployment rate is one of the most pressing challenges that Greece is currently facing. The unemployment rate increased from about $8 \%$ in 2008 to $27.5 \%$ in 2013; it then declined slightly to $26.5 \%$ in 2014 . According to the European Commission (2016), the unemployment rate declined to $25.1 \%$ in 2015 and is projected to decline further, reaching to $24.0 \%$ in 2016 . However, it still remains at unsustainably high levels. The unemployment problem is particularly acute among young individuals, who currently face unemployment rates close to $50 \%$. Moreover, more than two thirds of the currently unemployed are without a job for a period of more than 12 months, so they are classified as long-term unemployed.

The unemployment problem can have severe economic and social repercussions, in terms of the marginalization of the people and groups involved in it, and in terms of the human capital erosion, which undermines the future growth prospects of the Greek economy. Moreover, high and persistent unemployment puts additional strains on the social security system and the public finances in Greece.

Motivated by the above developments, this paper investigates the determinants of unemployment dynamics in Greece. In particular, it studies the role played by inflows and outflows in shaping recent unemployment developments. Moreover, the paper examines the relationship between unemployment and vacancies (Beveridge curve) in Greece in order to understand whether the rise in unemployment reflects cyclical and/ or structural developments.

(C) 2016 Tagkalakis. Open Access This article is distributed under the terms of the Creative Commons Attribution 4.0 International License (http://creativecommons.org/licenses/by/4.0/), which permits unrestricted use, distribution, and reproduction in any medium, provided you give appropriate credit to the original author(s) and the source, provide a link to the Creative Commons license, and indicate if changes were made. 
According to Shimer (2005) and Hall (2005), the outflow rate has been found to have the primary role in accounting for unemployment dynamics in the USA. Shimer (2012) has shown that since 1948, the outflow rate from unemployment has accounted for three fourths of the fluctuation in the unemployment rate in the USA and the inflow rate to unemployment for one fourth. Since 1987, the contribution of the outflow rate is estimated to have reached about $90 \%$ of the variability of the US unemployment, while the contribution from the inflow rate is considered to be quantitatively irrelevant. This induces Shimer to conclude that there are substantial fluctuations in the outflow rate over the business cycle, while the inflow rate is acyclic.

Fujita and Ramey (2009) and Elsby et al. (2009) using US data and Petrogolo and Pissarides (2008) and Smith (2011) using UK data have challenged the conclusions of Shimer $(2005,2012)$ by showing that inflows to unemployment are quantitatively relevant for unemployment dynamics. Moreover, according to Smith (2011), at times of rising unemployment, the inflow rate is the most relevant determinant of unemployment dynamics, while at times of declining unemployment, the outflow rate matters the most for unemployment dynamics.

Nevertheless, Elsby et al. (2013) have shown that there is a natural partition of OECD economies in two groups, i.e., those that have more and less flexible labor markets. Anglo-Saxon and Nordic economies display high exit rates from unemployment, with monthly hazard rates exceeding $20 \%$, whereas Continental European economies have exit rates that are less than $10 \%$. Turning to inflow rates to unemployment, Anglo-Saxon and Nordic economics have monthly inflow rates of about $1.5 \%$, while the inflow rates decline to $0.5-1 \%$ in Continental Europe. In addition, Elsby et al. (2013) show that the relative contribution of inflow and outflow rates to unemployment fluctuations is about 20:80 in Anglo-Saxon economies a result closer to the earlier US findings. In case of Nordic and Continental European economies, the authors observe a 50:50 inflow/outflow split.

Bonthuis et al. (2013) study unemployment and vacancy developments in the euro area at the aggregate and country level in order to identify whether the recent rise in unemployment reflects cyclical or structural factors such as growing mismatches across euro area labor markets. They find a significant outward shift in the euro area Beveridge curve during the Great Recession, but there is considerable heterogeneity at the country level. For example, there is an outward shift in the Beveridge curve for Spain and France and an inward shift for Germany. In case of Greece, there is some evidence of an outward shift in the Beveridge curve during the recent crisis.

Following the abovementioned studies, it is very important to identify the determinants of the unemployment movements in recent years in Greece. If the changes in the inflow rate to unemployment are the most important factor behind the unemployment fluctuation, then a pick-up in economic activity will contribute to the stabilization and eventual decline of the unemployment rate. However, if the changes in the outflow rate from the unemployment matter as well, then economic recovery will result in lower unemployment only if it is associated with job creation. In addition, if there is an outward shift in the Beveridge curve, then this would imply growing mismatches in the labor market, possibly reflecting the rise in long-term unemployment. In this case, a jobless recovery would be associated with persistently high unemployment rate. Such a development could lead to the erosion of human capital and the deterioration of the long-term prospects of the Greek economy. 
We use Labor Force Survey (LFS) data over the period 2001 Q1-2015 Q2 to investigate the determinants of unemployment dynamics in Greece. Building on Smith (2011), we find that the inflow rate to unemployment accounts for the biggest part of unemployment variability over the sample period. However, focusing on the most recent crisis years, we find evidence pointing to the opposite direction, i.e., that the outflow rate from unemployment is a very important determinant of the variance of unemployment. The economic recession alongside labor market reforms raised the inflow rate to and decreased the outflow rate from unemployment in the early crisis years (until mid-2012). Thereafter, the gradual normalization of economic conditions and the adoption of further structural reforms raised the outflow rate and led to drop in the inflow rate to unemployment, contributing to the slight fall in the unemployment rate in 2014-2015.

Impulse response functions based on a structural vector autoregressive (SVAR) analysis provide evidence for the negative effects of economic recession on the unemployment dynamics, i.e., the inflow rate to unemployment rises and the outflow rate from unemployment drops. In addition, the results of the SVAR analysis indicate that the negative effects of economic recession on the outflow from unemployment are slightly more protracted compared to those on the inflow rate. Cumulative dynamic multiplier functions from a VAR model suggest that structural reforms at times of deepening recession can aggravate the unemployment problem by raising the inflow and lowering the outflow rate, while structural reforms undertaken at times of gradual recovery or decelerating recession can be associated with an increase in the outflow and a decline in the inflow rate.

Building on the work of Bonthuis et al. (2013), we study unemployment and vacancy developments in Greece from 2004 Q1 till 2015 Q2. Our results are suggestive of the presence of an inverse relationship between unemployment and vacancies in Greece, which is driven by the post-2008 developments. The decline in, and the sectoral reallocation of, economic activity during the crisis years alongside with the adoption of less stringent employment protection legislation raised the unemployment rate and led to an outward shift in the Beveridge curve. However, the responsiveness of unemployment to vacancy developments has increased on account of structural reforms, which has led to an improvement in the efficiency of the matching process. This should facilitate a more rapid decline in unemployment when economic conditions improve and labor demand increases.

The paper is organized as follows. In Section 2, we discuss the data information and we construct the inflow rate to and the outflow rate from unemployment. In Section 3, we present the covariance contributions of inflow and outflow rates to unemployment variance. Section 4 discusses the unemployment and job vacancy developments in Greece and presents econometric evidence for the presence of a negatively sloping Beveridge curve. We then discuss in Section 5 the impact of economic recession on unemployment dynamics by means of a SVAR analysis, while in Section 6, we present evidence for the persistence of the unemployment rate following an increase in the inflow rate. The next section presents a first assessment of the impact of structural reforms on the inflow and outflow rates. Section 8 summarizes the main findings and concludes.

\section{Data}

We use Labor Force Survey data over the period 2000 Q1-2015 Q2 in order to calculate the unemployment inflows and outflows. ${ }^{1} \mathrm{We}$ employ data regarding the responses of participants on their current employment status (employed (E), unemployed (U), 
inactive (I)) which we then link with their responses in the recall question about their employment status (employed, unemployed, inactive) 1 year ago. ${ }^{2}$

As a next step, we calculate quarterly flows for the three employment statuses. For example, the number of flows from unemployment at time $t-1$ to employment at time $t$ is shown as $\mathrm{U}_{t-1} \mathrm{E}_{t}$. Dividing this by the number of unemployed at time $t-1\left(\mathrm{U}_{t-1}\right)$, we obtain the quarterly flow rate $\mathrm{U}_{t-1} \mathrm{E}_{t} / \mathrm{U}_{t-1}$, which reflects the quarterly probability of making the relevant transition. The quarterly flow rates are seasonally adjusted (ARIMA X12). In a similar manner, we construct the remaining flow rates, e.g., $\mathrm{E}_{t-1} \mathrm{U}_{t} / \mathrm{E}_{t-1}$ and $\mathrm{U}_{t-1} \mathrm{I}_{t} / \mathrm{U}_{t-1}$.

Building on Petrogolo and Pissarides (2008) and Smith (2011), we calculate the instantaneous transition rates. For example, $\lambda_{t_{-} \mathrm{UE}}\left(\lambda_{t_{\mathrm{U}} \mathrm{E}}=-\ln \left(1-\frac{U_{t-1} * E_{t}}{U_{t-1}}\right)\right)$ represents the instantaneous transition rate from unemployment to employment and is called job finding rate; $\lambda_{t_{-} \mathrm{EU}}$ is transition rate from employment to unemployment and is called job separation rate. In order to calculate the total inflow rate to unemployment $\left(s_{t}\right)$, we take into account both the job separation rate $\left(\lambda_{t \_\mathrm{EU}}\right)$ and the transition rate from employment (E) to inactivity (I) and the transition rate from inactivity (I) to unemployment (U). Hence,

$$
s_{t}=\lambda_{t_{-} \mathrm{EU}}+\frac{\lambda_{t_{-} \mathrm{EI}} * \lambda_{t_{-} \mathrm{IU}}}{\left(\lambda_{t \_\mathrm{IU}}+\lambda_{t_{\mathrm{IE}}}\right)}
$$

where the second term in Eq. (1) reflects the transition $\mathrm{E} \rightarrow \mathrm{I} \rightarrow \mathrm{U}$. Analogously, the total outflow rate from unemployment $\left(f_{t}\right)$ is calculated as the sum of the job finding rate $\left(\lambda_{t}\right.$ UE $)$ and the transition rate from unemployment to employment via inactivity. Therefore,

$$
f_{t}=\lambda_{t_{-} \mathrm{UE}}+\frac{\lambda_{t_{-} \mathrm{UI}} * \lambda_{t_{\text {IIE }}}}{\left(\lambda_{t_{-} \mathrm{IU}}+\lambda_{t_{-} \mathrm{IE}}\right)}
$$

where the second part of Eq. (2) reflects the transition $U \rightarrow I \rightarrow E$.

Figure 1 plots estimates of the total inflow and outflow rates, as well as the unemployment rate and the real GDP growth rate. The total inflow rate and the total outflow rate were on average at about 35 and $3 \%$, respectively, until the end of 2008 . However, after 2009-2010, driven by the deteriorating economic conditions, the total outflow rate and the total inflow rate followed distinct paths, i.e., decreasing and increasing, respectively. This trend continued until about 2012 Q2, when the outflow and inflow rates reached their minimum and maximum values, respectively, over the sample period, i.e., $10 \%$ for the outflow rate and $8 \%$ for the inflow rate. This period was characterized by high political polarization, the rise of uncertainty, and double national elections in May and June 2012.

Subsequently, both inflow and outflow rates improved in line with the bottoming out of recession and the gradually improving economic conditions, despite the fact that the unemployment rate kept rising until it reached a pick in 2013 Q3. Consequently, the inflow rate stood at about $5 \%$ and the outflow rate at about $17 \%$ in 2015 Q2, i.e., the last available observation.

The changes in the inflow and outflow rates (Fig. 1) reflect both cyclical and structural developments. The rapidly deteriorating economic conditions until the end 2011 


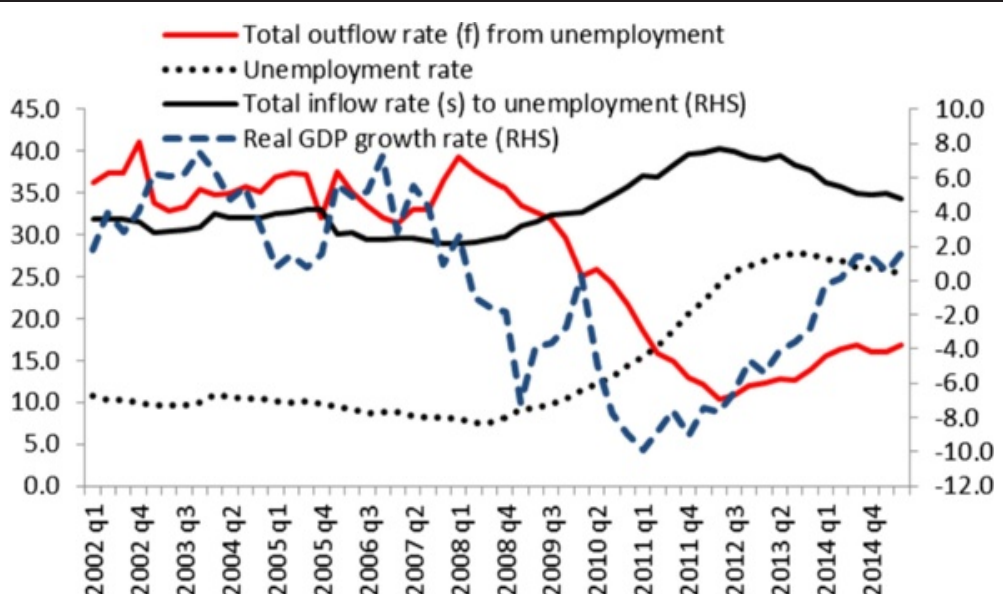

Fig. 1 Inflow rate to unemployment, outflow rate from unemployment, unemployment rate, real GDP growth rate (in \%). Source: Labor Force Survey, El.Stat; author's calculations

exerted a negative effect on labor market developments, lowering the outflow rate from and raising the inflow rate to unemployment. ${ }^{3}$ Following the double elections in 2012 Q2, uncertainty receded and economic conditions were normalized. As a consequence, both inflow and outflow rates improved.

However, during the period under examination, various structural reforms were implemented aiming at improving the flexibility of the labor market. The progress achieved is reflected in the reduction of employment protection legislation (EPL) index of the OECD which is shown in Fig. 2. The relaxation of the restriction in firing and hiring in late 2010-early 2011 (regarding the notice period for dismissal, the severance payments, etc.) allowed firms to cut labor costs by laying-off workers, without incurring high dismissal costs. This allowed many firms to continue stay afloat during bad economic times. However, it accelerated the increase in the inflow rate to unemployment $(s)$, while the decline in employment growth and the posted job vacancies on account of the recession contributed to the fall of the outflow rate from unemployment $(f)$. As a consequence, the unemployment rate increased from about $12.6 \%$ in 2010 Q3 to about $18 \% 1$ year later and skyrocketed to about $25 \% 2$ years later.

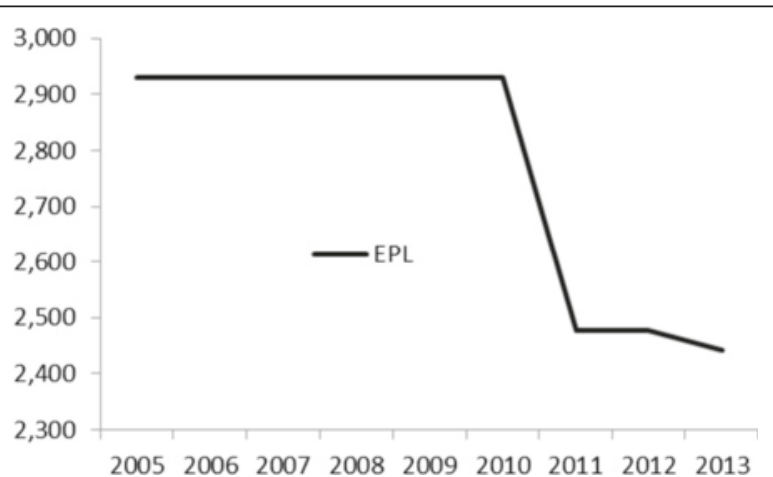

Fig. 2 Employment protection legislation (EPL) - reflecting flexibility in individual and collective dismissals. Note: source OECD. Lower values reflect a more flexible labor market 
The structural reforms that were initiated as part of the second Economic Adjustment Programme for Greece in 2012, i.e., the reduction in social security contributions in November 2012 and in July 2014, the activation of various training and internship labor market programs, the changes in the determination of minimum wages (involving a wage reduction of $22 \%$ for workers aged above 25 and a $32 \%$ reduction for workers below 25 years of age), the primacy given in firm level agreements which could set wages below those in the national collective agreement, etc., facilitated the reduction in nominal wages. These developments allowed firms to reduce labor costs through nominal wage cuts rather than labor shedding, which, in turn, led to decline in the inflow rate to unemployment. Furthermore, the new framework that was put in place, which allowed employers to hire new employees benefiting both from the reduction in nominal wages and the less regulated labor market, had a positive effect on labor demand. As a consequence, the job vacancy rate, after reaching its minimum value in 2013 Q2, started to rise thereafter, leading to an increase in the outflow rate from unemployment. The decline in the inflow rate to and the increase in the outflow rate from unemployment led to a small drop in the unemployment rate, i.e., to $26.5 \%$ in 2014 from its peak value of $27.5 \%$ in 2013.

Turning to the remaining transition rates (Figs. 3 and 4), we observe that the main determinants of the total inflow rate $(s)$ to and the total outflow rate $(f)$ from unemployment are the job separation $\left(\lambda_{\mathrm{EU}}\right)$ and the job finding rates $\left(\lambda_{\mathrm{UE}}\right)$, respectively. Nevertheless, from 2009 to 2010 onwards, the relevance of the transition from employment to unemployment via inactivity $(\mathrm{E} \rightarrow \mathrm{I} \rightarrow \mathrm{U})$ for the determination of the total inflow rate $(s)$ has increased. On the contrary, the transition from unemployment to employment via inactivity $(\mathrm{U} \rightarrow \mathrm{I} \rightarrow \mathrm{E}$ ) has a smaller effect on the total outflow rate from unemployment $(f)$.

Indeed, the transition rates from inactivity to unemployment $\left(\lambda_{\mathrm{IU}}\right)$ and from inactivity to employment $\left(\lambda_{\mathrm{IE}}\right)$ hovered around $2 \%$ before the crisis period; however, thereafter, they followed a diverse path with $\lambda_{\mathrm{IU}}$ increasing to about $3 \%$ and $\lambda_{\mathrm{IE}}$ declining to about $1 \%$ (Fig. 4). These movements reflect the fact that on account of the recent crisis, individuals that were previously inactive were obliged (possibly because of unemployment

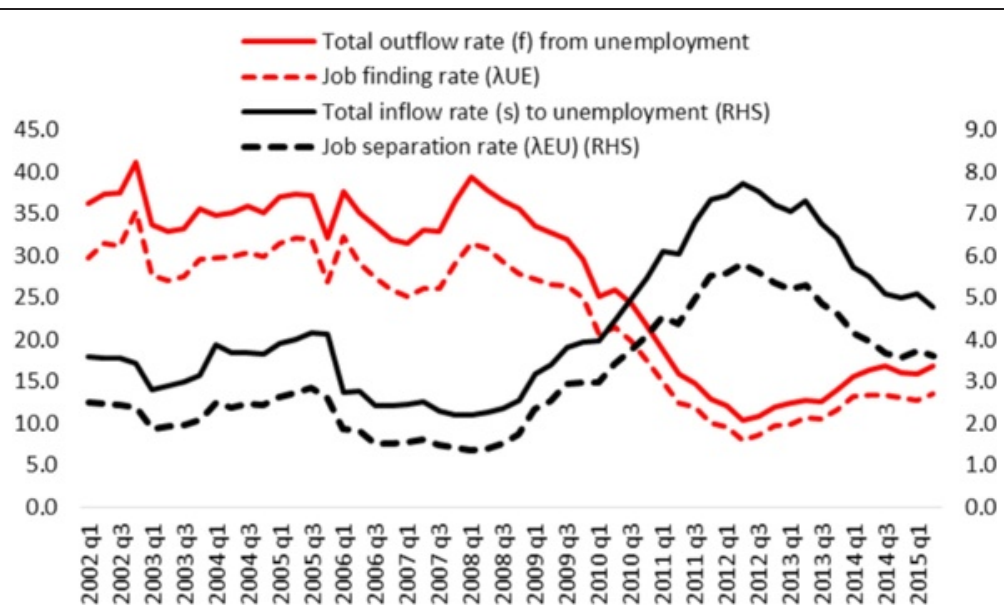

Fig. 3 Total inflow and outflow rates and job separation and finding rates (in \%). Source: Labor Force Survey, El.Stat; author's calculations 


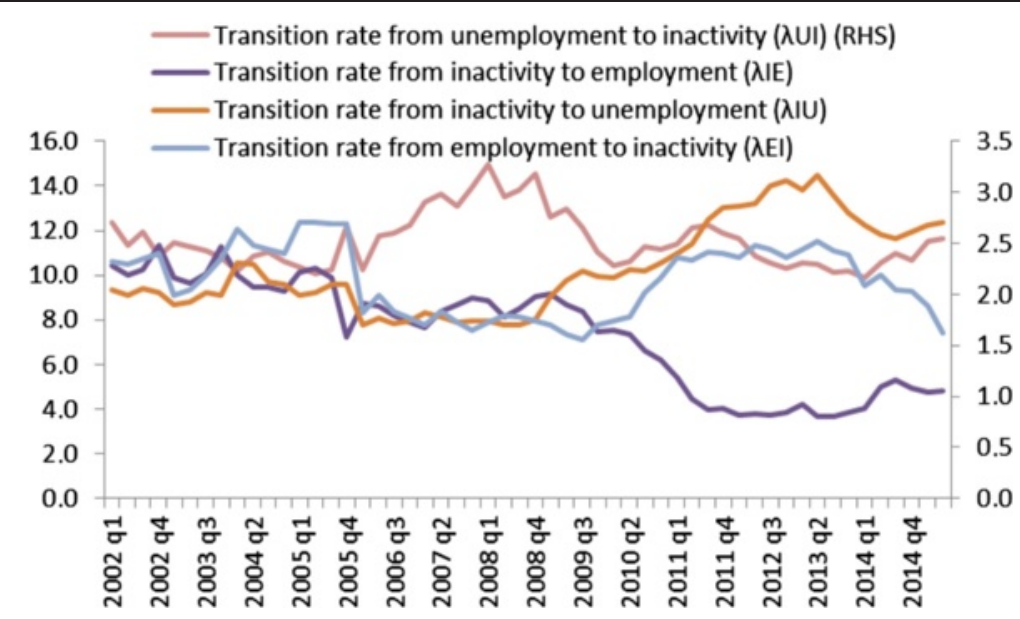

Fig. 4 Transition rates into and out of inactivity (in \%). Source: Labor Force Survey, El.Stat; author's calculations

in family members, wage cuts, etc.) to enter the labor market and seek employment and consequently to be recorded as unemployed. In addition, the evolution of the transition rate from unemployment to inactivity $\left(\lambda_{\mathrm{UI}}\right)$ indicates that there is limited discourage worker effect in the course of the recent crisis. However, there is a slight uptick in the relevant transition rate $\left(\lambda_{\mathrm{UI}}\right)$ from 2014 Q1 until the end of the sample.

\section{Covariance contributions to unemployment variance}

Following the work of Smith (2011), we calculate the covariance $\left(\beta_{s}\right.$ and $\left.\beta_{f}\right)$ contribution of the inflow and outflow rate to the variance of steady state unemployment $u_{t_{s}}$ :

$$
u_{t \_s s}=\frac{s_{t}}{\left(s_{t}+f_{t}\right)}
$$

Changes in the inflow rate $(s)$ explain $58 \%$ of movements in steady state unemployment (Table 1). Changes in the job separation rate $\left(\lambda_{t_{-} \mathrm{EU}}\right)$ account for about $39 \%$ of the variation in steady state unemployment. The role of the outflow rate $(f)$ is lower, i.e., it accounts for about $41 \%$ of steady state unemployment variability with the biggest effect reflecting the job finding rate $\left(\lambda_{t_{-} \mathrm{UE}}\right)$ which explains $35 \%$ of the unemployment variability.

These findings resemble the ones reported by Smith (2011) for the UK (for the period 1988-2008), Hairault et al. (2015) for France (for the period 1990-2002), and Daouli

Table 1 Covariance contributions to steady state unemployment variance

\begin{tabular}{lll}
\hline$\beta$ & Transition rate & \\
\hline$\beta_{s}$ & Inflow rate to unemployment & 0.58 \\
$\beta_{f}$ & Outflow rate from unemployment & 0.41 \\
$\beta_{\text {EU }}$ & Job separation rate & 0.39 \\
$\beta_{\text {UE }}$ & Job finding rate & 0.35 \\
$\beta_{\text {EIU }}$ & Inflow via inactivity & 0.19 \\
$\beta_{\text {UIE }}$ & Outflow via inactivity & 0.06 \\
\hline
\end{tabular}

Notes: The sum of $\beta_{S}\left(=\beta_{\mathrm{EU}}+\beta_{\mathrm{EIU}}\right)$ and $\beta_{f}\left(=\beta_{\mathrm{UE}}+\beta_{\mathrm{UIE}}\right)$ do not add up to one due to the approximation error. Source: LFS, 2001 Q1 -2015 Q2 
et al. (2015) for Greece (for the period 1998-2013) and Bank of Greece (2015). Hence, contrary to the findings of Shimer $(2005,2012)$ for the USA, changes in the inflow rate do explain substantial part of unemployment dynamics. ${ }^{4}$

Next, we repeat the analysis that underlies the findings report in Table 1, but this time, we compute rolling 4 -year betas (i.e., $\beta_{s}, \beta_{f}$, etc.); Fig. 5 plots the findings. From the start of the period under investigation until the end of 2012, the inflow rate $(s)$ has the primary role in explaining the variability in steady state unemployment. However, from the period 2009 Q2 to 2013 Q1 onwards, the outflow rate $(f)$ accounts for the biggest part of the variability in steady state unemployment. It should be recalled that from 2013 onwards, the recession bottomed out and the structural reforms that were previously implemented started to bear fruit in terms of lower labor costs and more flexible labor markets. These developments improved labor prospects, despite the fact that the unemployment rate continued its upward path until 2013 Q3.

Overall, we find evidence that both the inflow and outflow rate play an important role in changing unemployment rates. At times of rising unemployment, the inflow rate to unemployment (job separation) plays the most important role, while the outflow from unemployment (job finding) plays the most important role at times of declining unemployment. Flexible labor relations are expected to contributed positively to both inflow and outflow rates. The results suggest that economic recovery is a necessary but not sufficient condition for the reduction of the very high unemployment rate. Economic recovery should go hand-in-hand with job creation to address the unemployment persistence problem.

\section{The Beveridge curve in Greece}

The importance of the job finding rate for the reduction of the unemployment rate discussed in the previous section is also related to the evolution of the job vacancy rate, which reflects labor demand by the business sector. ${ }^{6}$ Figure 6 plots the job vacancy rate

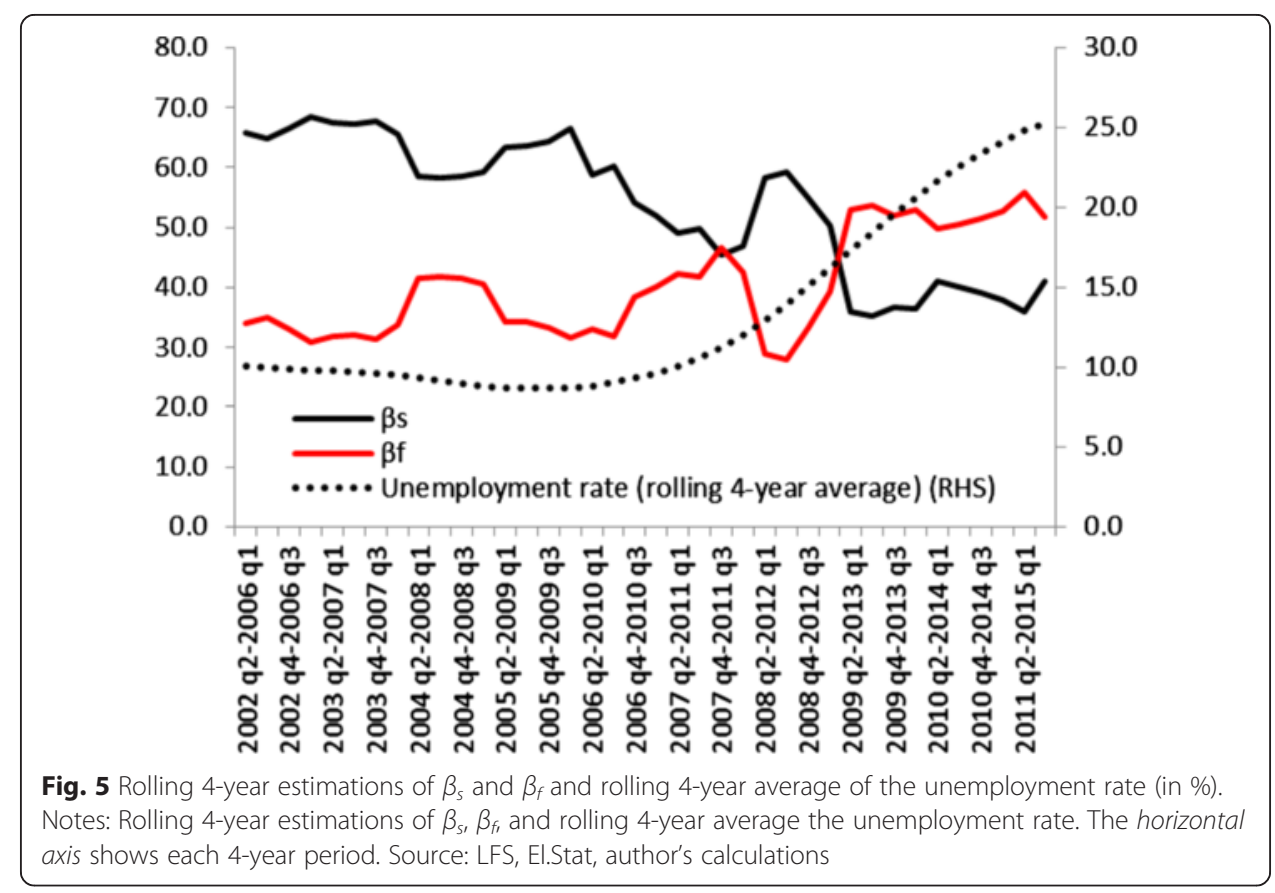




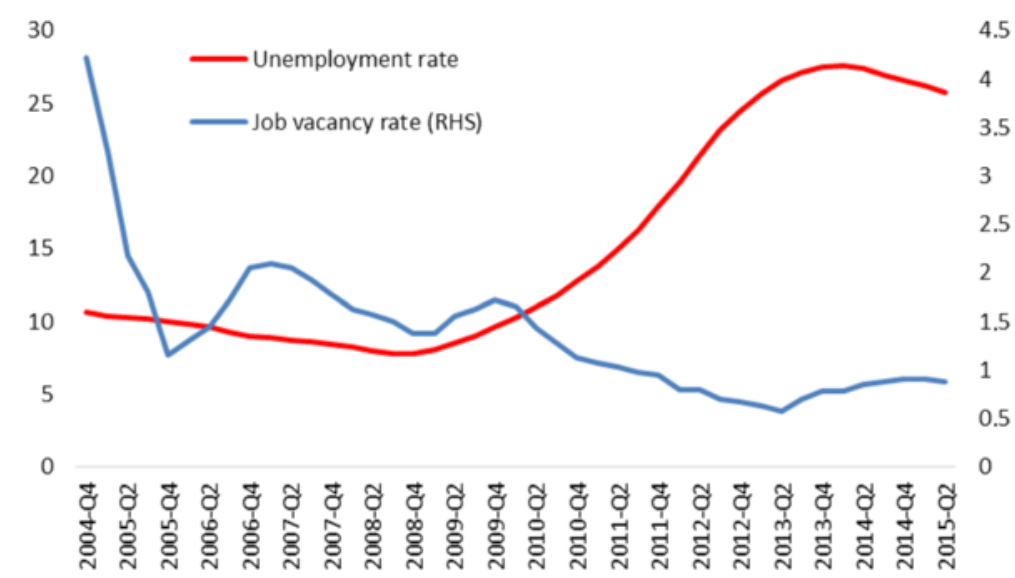

Fig. 6 Job vacancy rate and unemployment rate (in \%). Note: Job vacancy rate = posted vacancies/(posted vacancies + occupied posts), unemployment rate, age 15-74. To control for seasonality, the values reported for both the job vacancy rate and the unemployment rate are averages over four quarters, i.e., the observation for 2004 Q4 is the average of 2004 Q1-2004 Q4. Source: Eurostat, author's calculations

and the unemployment rate for the period 2004 Q4-2015 Q2. The rise in unemployment rate since 2009 went hand-in-hand with the decline in the job vacancy rate (which started already in late 2006). The job vacancy rate reached a trough in 2013 Q2. Subsequently, it trended upwards in line with the gradual decline in unemployment. Nevertheless, it still remains at levels that are below those recorded in 2005-2010. ${ }^{7}$

The Beveridge curve (see Fig. 7) reflects both the cyclical conditions and the efficiency of the labor market to match unemployed workers and available vacancies. The

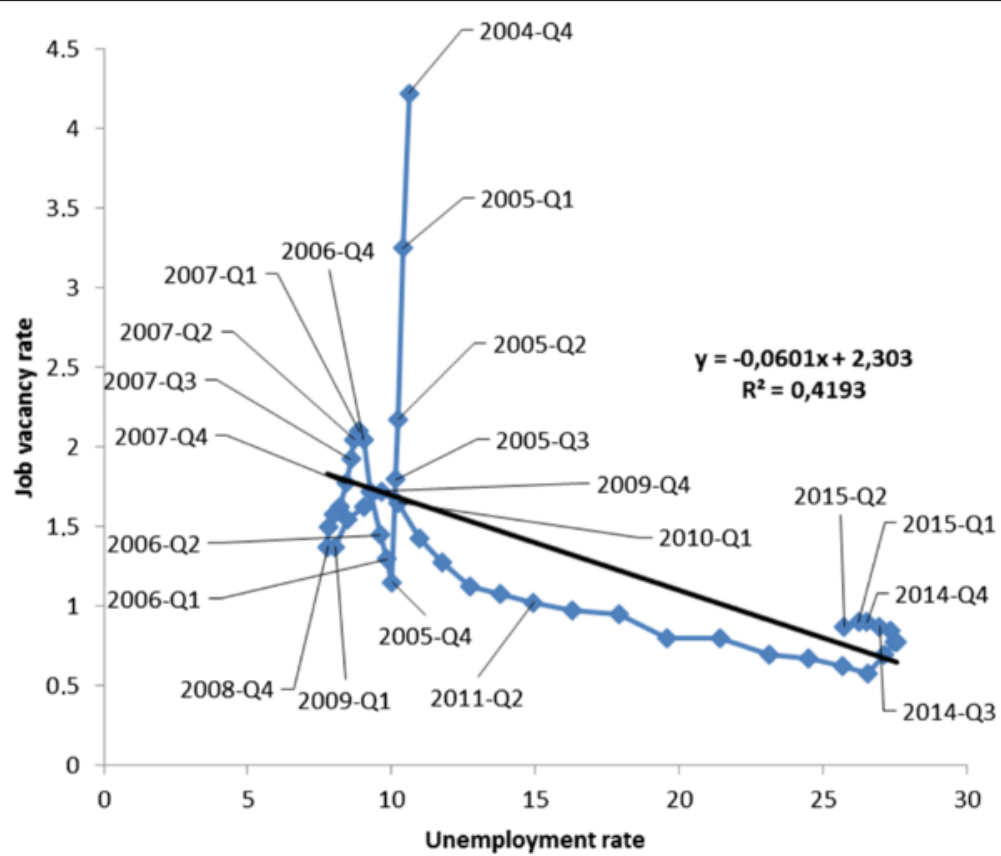

Fig. 7 The Beveridge curve 2004 Q4-2015 Q2 (in \%). Note: To control for seasonality, the values reported for both the job vacancy rate and the unemployment rate are averages over four quarters, i.e., the observation for 2004 Q4 is the average of 2004 Q1-2004 Q4. Source: Eurostat, author's calculations 
Beveridge curve has the usual downward slopping trend (Fig. 7). However, the picture that emerges from the start of the sample in 2004 till late 2009 is rather mixed. This is also reflected in the upward slopping Beveridge curve in Fig. 8 covering the period 2004 Q4-2009 Q3. The positive slope is primarily due to the 2004-2005 observations. During that time, the unemployment rate remained close to $10 \%$ despite the very high job vacancy rates. This development indicates the presence of structural unemployment, i.e., a significant mismatch between the attributes of the unemployed and the posted vacancies, as well as significant restrictions in the labor market, which reduce competition between workers for the available jobs. On the other hand, given that the vacancy data collection for Greece (and the EU in general) started in 2004, it is likely that the first observations might contain some errors.

If we drop the first three observation of the first sub-sample and consider the period 2005 Q4-2009 Q3, the slope of the Beveridge curve becomes negative (see Fig. 9). A closer examination of the period 2006-2008 reveals a decline in unemployment from about $9.5-10 \%$ to about $8-8.5 \%$, although the job vacancy rate remains steady at about $1.5-2 \%$. This is suggestive of a slight inward shift of the Beveridge curve.

From late 2009 onwards, on account of the deteriorating economic conditions, the unemployment and the job vacancy rates followed increasing and decreasing paths, respectively. Two changes are discernible in the Beveridge curve over the recent crisis years: First, there is an outward shift in the Beveridge curve-a job vacancy rate of $1.1 \%$ corresponds to a higher unemployment rate than before (i.e., 13-14 \% compared to $10 \%$ in 2005 Q4-see Fig. 7). Second, the negative slope of the Beveridge curve has been reduced-this is evident from the slope of the trend line in Fig. 10 compared to the one in Fig. 7. As depicted in Fig. 10, the deterioration of economic conditions leads to an increase in unemployment and a decline in the vacancy rate, i.e., a movement along the Beveridge curve.

The bottoming out of recession and the gradual decline in the unemployment from 2014 onwards is associated with a marginal pick-up in the job vacancy rate. Nevertheless, a potentially disturbing picture emerges, i.e., a slight outward shift in the Beveridge

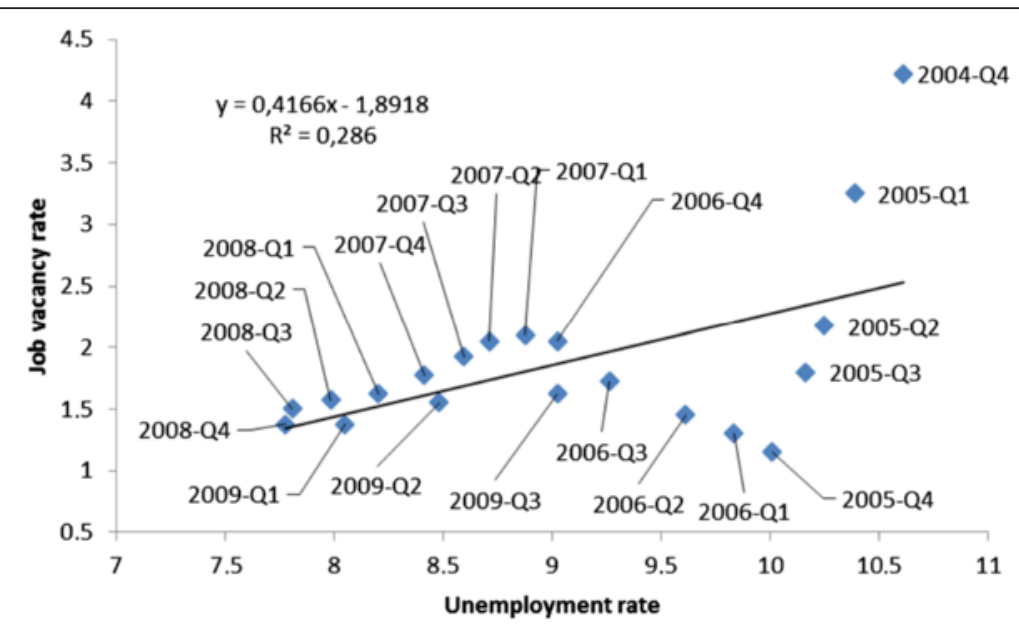

Fig. 8 The Beveridge curve 2004 Q4-2009 Q3 (in \%). Note: To control for seasonality, the values reported for both the job vacancy rate and the unemployment rate are averages over four quarters. Source: Eurostat, author's calculations 


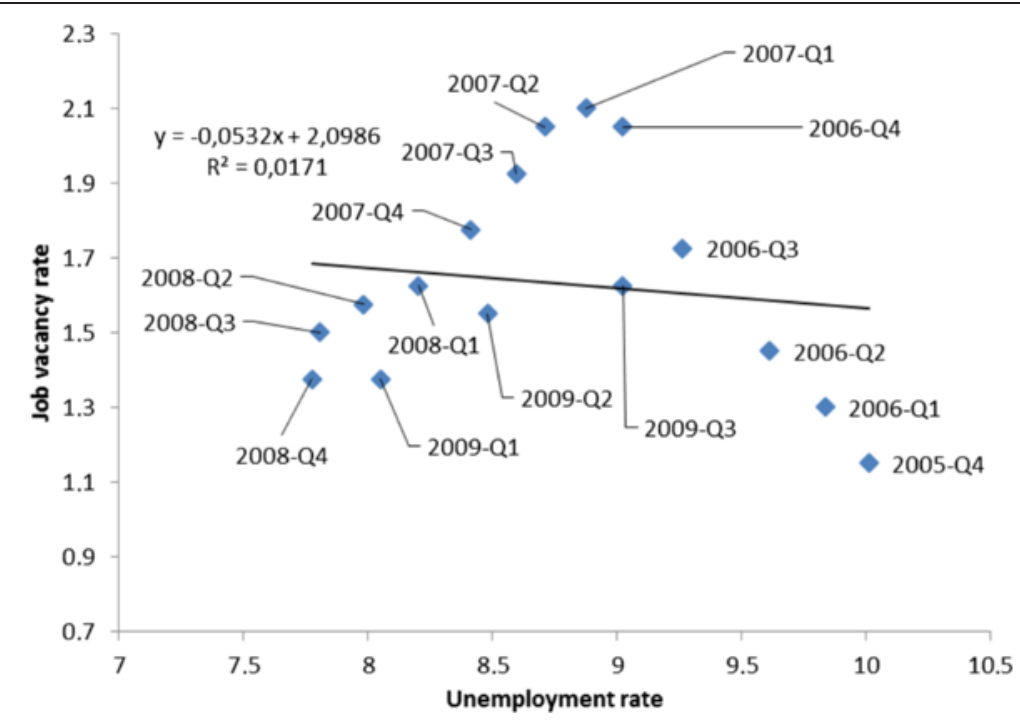

Fig. 9 The Beveridge curve 2005 Q4-2009 Q3 (in \%). Note: To control for seasonality, the values reported for both the job vacancy rate and the unemployment rate are averages over four quarters. Source: Eurostat, author's calculations

curve despite the small decline in unemployment (vis-à-vis its high levels recorded in 2013). A job vacancy rate of $0.9 \%$ is currently associated with an unemployment rate that is around $25-26 \%$ compared to $17 \%$ at the end of 2011 .

Overall, despite the labor market reforms that were implemented since 2010 aiming at enhancing the matching efficiency of the Greek labor market, the large structural changes and the sectoral reallocation of economic activity on account of the recent crisis have created increased (skill, sectoral, locational) mismatches between unemployed and posted vacancies leading to very high structural unemployment. Based on LFS data,

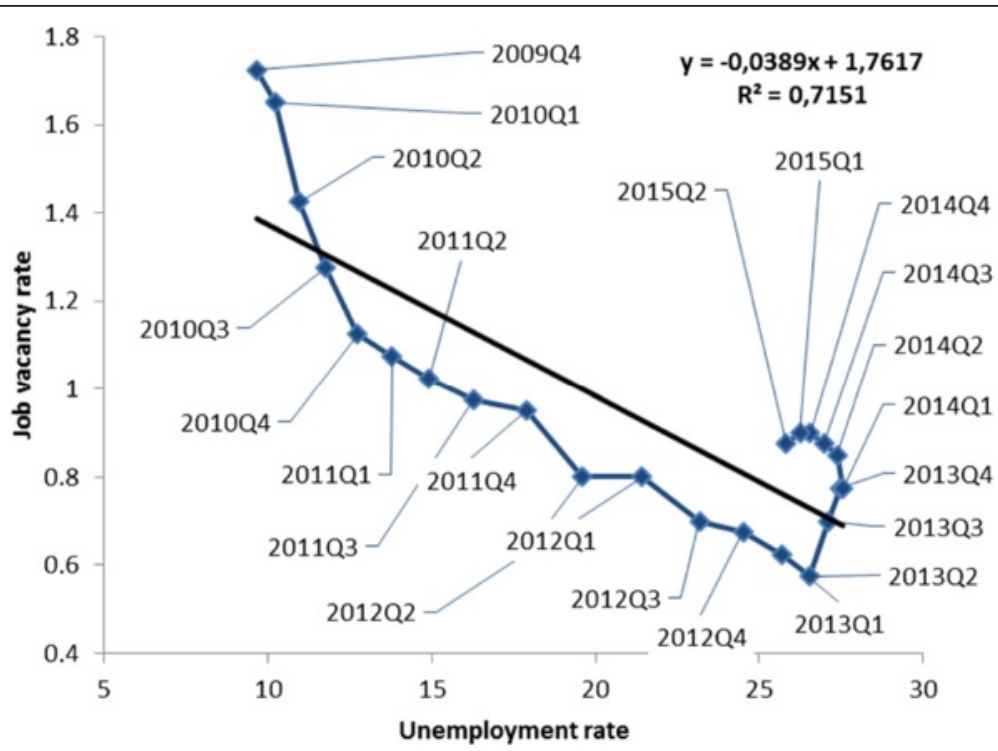

Fig. 10 The Beveridge curve 2009 Q4-2015 Q2 (in \%). Note: To control for seasonality the values reported for both the job vacancy rate and the unemployment rate are averages over four quarters. Source: Eurostat, author's calculations 
more than two thirds of the currently unemployed are in a state of unemployment for a period of more than 12 months, thus being classified as long-term unemployed.

On the other hand, it should be taken into account that at times, job vacancies tend to move quicker than unemployment. This can lead to a sudden drop (or jump) in vacancies while unemployment doesn't react (yet). This does not necessarily mean that the Beveridge curve has shifted in or out, these issues will be discussed in more detail in the next section.

\subsection{Econometric analysis}

Building on the work of Bonthuis et al. (2013) and the studies cited therein, we investigate the relationship between the unemployment rate and the job vacancy rate. We rely on seasonally adjusted data covering the period 2004 Q1-2015 Q2 in order to establish statistical significance for the findings suggested by the visual inspection of Fig. 7, in particular, the effect of the recent crisis and the role of structural reforms. ${ }^{8}$ The benchmark model is: ${ }^{9}$

$$
U_{t}=\alpha+\beta_{1} * U_{t-1}+\beta_{2} * V_{t}+\beta_{3} * V_{t}^{2}+\varepsilon_{t}
$$

where $U_{t}$ is the unemployment rate, the lagged unemployment rate controls for unemployment persistence, ${ }^{10} V_{t}$ is the job vacancy rate, and the quadratic term $V_{t}^{2}$ reflects the convexity of the Beveridge curve. As pointed by Bonthuis et al. (2013), it captures non-linearities in the Beveridge curve, i.e., a smaller unemployment rate reaction when the job vacancy rate are very high (as in the early years of our sample), but higher reaction when vacancies are low (as in the latter years of our sample). We consider several variants of Eq. (4). For example, we estimate:

$$
U_{t}=\alpha+\beta_{1} * U_{t-1}+\beta_{2} * V_{t}+\beta_{3} * V_{t}^{2}+\beta_{4} * \operatorname{CRISIS}_{t}+\beta_{5} * E P L_{t}+\varepsilon_{t}
$$

CRISIS is a dummy variable capturing the impact of the negative real GDP growth in the Greek economy, and it would imply an outward shift in the Beveridge curve. It takes a value of 1 at times of negative annual real GDP growth rate $\left(y_{t}-\mathrm{y}_{t-4}<0\right.$, where $y_{t}$ is the quarterly real GDP) and 0 otherwise. The EPL index of the OECD (see Fig. 2) measures the strictness of employment protection legislation and accounts for the impact of the labor market legislative changes on the position of the Beveridge curve. ${ }^{11}$ Alternatively, for the sake of better understanding the results, we also employ the $R E$ FORMS index which reflects the structural labor market reforms that were undertaken in recent years. This index is simply the inverse of the EPL index (1/EPL). Therefore, higher values of REFORMS are interpreted as establishment move towards a more flexible labor market.

We also consider interaction terms between the job vacancy rate, the CRISIS dummy $\left(\right.$ CRISIS $\left._{t}{ }^{*} V_{t}\right)$, and the EPL index $\left(E P L_{t}{ }^{*} V_{t}\right)$. We estimate each interaction term at a time in Eqs. (6) and (7):

$$
\begin{aligned}
U_{t}= & \alpha+\beta_{1} * U_{t-1}+\beta_{2} * V_{t}+\beta_{3} * V_{t}^{2}+\beta_{4} * C R I S I S_{t}+\beta_{5} * E P L_{t}+\beta_{6} \\
& * \operatorname{CRISIS}_{t} * V_{t}+\varepsilon_{t} \\
U_{t}= & \alpha+\beta_{1} * U_{t-1}+\beta_{2} * V_{t}+\beta_{3} * V_{t}^{2}+\beta_{4} * \operatorname{CRISIS}_{t}+\beta_{5} * E P L_{t}++\beta_{6} \\
& * E P L_{t} * V_{t}+\varepsilon_{t}
\end{aligned}
$$

The interaction term $\left(\operatorname{CRISIS}_{t}{ }^{*} V_{t}\right)$ captures changes in the slope of the Beveridge curve, i.e., changes in the efficiency of the matching process that are attributed to the 
crisis. In Eq. (6), we calculate the "Effect of the job vacancy rate if CRISIS $=1$ " as the sum of $\beta_{2}+\beta_{6}$.

The interaction term $\left(E P L_{t}{ }^{*} V_{t}\right)$ captures changes in the slope of the Beveridge curve, i.e., changes in the efficiency of the matching process, that are attributed to changes in labor market regulation. For example, a more flexible labor market should be expected to increase the responsiveness of unemployment to vacancy developments. In Eq. (7), we calculate the "Effect of the job vacancy rate conditional on EPL" as the sum of $\beta_{2}+\beta_{6}{ }^{*} E P L_{t}$, (where EPL can be evaluate at its sample average value).

In Eq. (8), we incorporate a full set of interaction terms that controls both for the interaction of job vacancy rate with the CRISIS dummy variable and the EPL index, as well as for the joint interaction between CRISIS, EPL, and job vacancy rate:

$$
\begin{aligned}
U_{t}= & \alpha+\beta_{1} * U_{t-1}+\beta_{2} * V_{t}+\beta_{3} * V_{t}^{2}+\beta_{4} * C R I S I S_{t}+\beta_{5} * E P L_{t}+\beta_{6} * C R I S I S_{t} * V_{t} \\
& +\beta_{7} * E P L_{t} * V_{t}+\beta_{8} * C R I S I S * E P L * V_{t}+\beta_{9} * C R I S I S * E P L_{t}+\varepsilon_{t}
\end{aligned}
$$

Following European Commission (2015), we calculate the following: (1) the "Effect of the job vacancy rate conditional on EPL if CRISIS $=1$ " as the sum of $\left(\beta_{2}+\beta_{6}\right)+$ $\left(\beta_{7}+\beta_{8}\right) * E P L_{t}$, and (2) the "Effect of the job vacancy rate conditional on EPL if CRISIS $=0$ " as the sum of $\beta_{2}+\beta_{7}{ }^{*} E P L_{t}$ (where EPL can be evaluate at its sample average value).

The main set of results is reported in Table 2. The coefficient on the lagged unemployment rate is large and highly significant, indicating considerable unemployment persistence. Moreover, the coefficient is strictly below 1 at all times (see columns 1-6) contrary to the findings of Bonthuis et al. (2013) who find a coefficient above 1 (suggesting a not well-defined Beveridge curve for Greece). Starting from the baseline specification of Eq. (4), we find that the job vacancy rate, as expected, has a negative coefficient, which is an evidence for the inverse relationship between the unemployment rate and the job vacancy rate (see column 1, Table 2). The squared job vacancy rate has a positive and statistically significant coefficient (see column 1), suggesting that the convexity condition of the Beveridge curve holds. There is a small unemployment response when labor demand is strong and job vacancies are high (the period 2004-2005) and a stronger unemployment response when job vacancies are low (the recent crisis years). However, both the size and the statistical significance of the coefficient of the squared job vacancy rate decline when we take into account other factors such the CRISIS dummy variable and the EPL index and their interactions with the job vacancy rate (see columns 2-6).

The impact of the CRISIS dummy variable is both positive and statistically significant (see columns 2-4, Table 2), implying an outward shift of the Beveridge curve in times of economic recession. The interaction term CRISIS*V is negative and statistically significant (see column 3). At the same time, the coefficient of the job vacancy rate remains negative but it is not statistically significant. Consequently, the "effect of the job vacancy rate if CRISIS $=1$ " is negative $(-1.05)$ and highly statistically significant in column 4. This implies an increase in the responsiveness of the unemployment to vacancy developments over the recent crisis. Hence, the inverse relationship between unemployment and vacancies, which underlies the Beveridge curve, is primarily due to 
Table 2 Beveridge curve estimations (whole sample 2004 Q1-2015 Q2)

\begin{tabular}{|c|c|c|c|c|c|c|}
\hline & 1 & 2 & 3 & 4 & 5 & 6 \\
\hline Dependent variable & Unemployment rate & & & & & \\
\hline Unemployment rate $_{t-1}$ & $0.967(39.94)^{* * *}$ & $0.894(25.58)^{* * *}$ & $0.977(49.28)^{* * *}$ & $0.971(54.30)^{* * *}$ & $0.853(27.40)^{* * *}$ & $0.885(23.13)^{* * *}$ \\
\hline Job vacancy rate ${ }_{t}$ & $-1.342(-2.24)^{* *}$ & $-0.586(-1.31)$ & $-0.657(-1.36)$ & $-0.095(-0.22)$ & $-6.620(-2.74)^{* * *}$ & $-0.835(-0.45)$ \\
\hline Job vacancy rate ${ }_{t}^{2}$ & $19.878(2.03)^{* *}$ & $10.470(1.41)$ & $11.037(1.38)$ & $2.095(0.31)$ & $12.139(1.24)$ & $0.896(0.14)$ \\
\hline $\mathrm{CRISIS}_{t}$ & & $0.007(3.91)^{* * *}$ & $0.008(4.11)^{* * *}$ & $0.019(4.07)^{* * *}$ & & $0.015(0.44)$ \\
\hline $\mathrm{EPL}_{t}$ & & $-0.022(-2.54)^{* *}$ & & & $-0.049(-2.74)^{* * *}$ & $-0.028(-2.19)^{* *}$ \\
\hline Job vacancy rate* ${ }^{*}$ ISIS ${ }_{t}$ & & & & $-0.954(-2.83)^{* * *}$ & & $-1.807(-0.58)$ \\
\hline Job vacancy rate* $E P L_{t}$ & & & & & $2.086(2.00)^{*}$ & $0.308(0.41)$ \\
\hline CRISIS*EPL ${ }_{t}$ & & & & & & $0.002(0.11)$ \\
\hline Job vacancy rate ${ }^{*} C R I S I S * E P L$ & & & & & & $0.305(0.25)$ \\
\hline Constant term & $0.022(2.31)^{* *}$ & $0.076(2.87)^{* * *}$ & $0.008(1.15)$ & $0.003(0.49)$ & $0.163(3.52)^{* * *}$ & $0.086(0.47)$ \\
\hline Effect of job vacancy if CRISIS $=1$ & & & & $-1.050532(-2.77)^{* * *}$ & & \\
\hline $\begin{array}{l}\text { Effect of job vacancy conditional } \\
\text { on EPL }\end{array}$ & & & & & $-4.534(-3.25)^{* * *}$ & \\
\hline $\begin{array}{l}\text { Effect of job vacancy conditional } \\
\text { on EPL if CRISIS }=1\end{array}$ & & & & & & $-2.029(-1.38)$ \\
\hline $\begin{array}{l}\text { Effect of job vacancy conditional } \\
\text { on } \\
\text { EPL if CRISIS }=0\end{array}$ & & & & & & $-0.528(-0.47)$ \\
\hline Obs & 46 & 46 & 46 & 46 & 46 & 46 \\
\hline$F$-test ( $p$ value) & $F(3,42)=1371.26(0.000)$ & $F(5,40)=1447.58(0.0000)$ & $F(4,41)=1431.98(0.000)$ & $F(5,40)=1472.98(0.0000)$ & $F(5,40)=1322.13(0.0000)$ & $F(9,36)=2090.63(0.0000)$ \\
\hline$R^{2}$ & 0.9921 & 0.9954 & 0.9944 & 0.9951 & 0.9942 & 0.9960 \\
\hline
\end{tabular}

Note: Standard errors are corrected for autocorrelation using Newey-West procedure. ***,**, * denote statistical significance at 1,5 , and $10 \%$ levels, respectively ( $t$-statistics in parenthesis). The effect of job vacancy if CRISIS $=1$ is the non-linear combination: Job vacancy rate + job vacancy rate*CRISIS (z-statistic in parenthesis). The effect of job vacancy conditional on EPL is the non-linear combination: Job vacancy rate + Job vacancy rate*EPL (z-statistics in parenthesis). The effect of job vacancy conditional on EPL if CRISIS $=1$ is the non-linear combination: Job vacancy rate + Job vacancy rate*EPL + job vacancy rate $(z$-statistics in parethesis). The effect of job vacancy conditional on EPL if CRISIS $=0$ is the non-linear combination: Job vacancy rate + Job vacancy rate*EPL ( $z$-statistics in parenthesis) 
the more recent economic developments. The visual inspection of Figs. 7-10 has already pointed to this conclusion. ${ }^{12}$

The index EPL has a negative and statistical significant coefficient (see columns 2, 5-6), suggesting that structural reforms (a lower EPL value) induce an outward shift of the Beveridge curve, i.e., they raise unemployment for the same level of job vacancies. Similarly, as reported in column 1 of Table 3, the REFORMS index has a positive and statistically significant coefficient, implying that more flexible labor markets are associated with higher unemployment rate.

The interaction term EPL*V has a positive coefficient estimate (column 4, Table 2), while the coefficient estimate of the job vacancy rate is negative and statistically significant (column 4, Table 2). As a consequence, the "effect of the job vacancy rate conditional on EPL" in column 4 is negative $(-4.534)$ and statistically significant. This is suggestive of an increase in the responsiveness of unemployment to vacancy developments on account of structural reforms that reduce the EPL index, i.e., an improvement in the efficiency of the matching process. Similarly, as reported in column 2 of Table 3, the "effect of the job vacancy rate conditional on REFORMS" is negative (-8.952) and statistically significant-i.e., labor market reforms raise the responsiveness of unemployment to vacancy developments.

In column 6 (Table 2), we present the findings that correspond to Eq. (8), where we control for the joint interaction between the CRISIS dummy variable, the EPL index,

Table 3 Beveridge curve estimations with REFORM variable (whole sample 2004 Q1-2015 Q2)

\begin{tabular}{|c|c|c|c|}
\hline & 1 & 2 & 3 \\
\hline Dependent variable & Unemployment rate & & \\
\hline Unemployment rate $_{t-1}$ & $0.894(24.98)^{* * *}$ & $0.851(26.21)^{* * *}$ & $0.884(22.48)^{* * *}$ \\
\hline Job vacancy rate ${ }_{t}$ & $-0.600(-1.34)$ & $3.724(1.31)$ & $0.664(0.35)$ \\
\hline Job vacancy rate ${ }_{t}^{2}$ & $10.690(1.43)$ & $12.499(1.27)$ & $0.959(0.14)$ \\
\hline $\mathrm{CRISIS}_{t}$ & $0.007(3.93)^{* * *}$ & & $0.024(0.60)$ \\
\hline $\mathrm{REFORMS}_{t}$ & $0.130(2.50)^{* *}$ & $0.299(2.67)^{* * *}$ & $0.164(2.17)^{* *}$ \\
\hline Job vacancy rate ${ }^{*} \mathrm{CRISIS}_{t}$ & & & $-0.361(-0.12)$ \\
\hline Job vacancy rate*REFORMS $S_{t}$ & & $-12.677(-1.96)^{*}$ & $-1.796(-0.40)$ \\
\hline CRISIS*REFORMS $_{t}$ & & & $-0.0107(-0.12)$ \\
\hline $\begin{array}{l}\text { Job vacancy } \\
\text { rate* }^{*} \text { RISIS*REFORMS }\end{array}$ & & & $-1.718(-0.23)$ \\
\hline Constant term & $-0.031(-1.72)^{*}$ & $-0.082(-1.82)^{*}$ & $-0.049(-1.72)$ \\
\hline $\begin{array}{l}\text { Effect of job vacancy conditional } \\
\text { on REFORMS }\end{array}$ & & $-8.952(-2.45)^{* *}$ & \\
\hline $\begin{array}{l}\text { Effect of job vacancy conditional } \\
\text { on REFORMS if CRISIS }=1\end{array}$ & & & $-3.210(-0.90)$ \\
\hline $\begin{array}{l}\text { Effect of job vacancy conditional } \\
\text { on REFORMS if CRISIS }=0\end{array}$ & & & $-1.131(-0.43)$ \\
\hline Obs & 46 & 46 & 46 \\
\hline$F$-test ( $p$ value) & $F(5,40)=1405.20(0.000)$ & $F(5,40)=1281.60(0.000)$ & $F(9,36)=2092.16(0.000)$ \\
\hline$R^{2}$ & 0.9953 & 0.9941 & 0.9959 \\
\hline
\end{tabular}

Note: Standard errors are corrected for autocorrelation using Newey-West procedure. ${ }^{* * *},{ }^{* *},{ }^{*}$ denote statistical significance at 1,5 , and $10 \%$ levels, respectively ( $t$-statistics in parenthesis). The effect of job vacancy conditional on REFORM is the non-linear combination: Job vacancy rate + Job vacancy rate*REFORM ( $z$-statistics in parenthesis). The effect of job vacancy conditional on REFORM if CRISIS $=1$ is the non-linear combination: Job vacancy rate + Job vacancy rate ${ }^{*}$ REFORM + job vacancy rate ${ }^{*}$ CRISIS + job vacancy rate ${ }^{*}$ CRISIS*REFORM ( $z$-statistics in parenthesis). The effect of job vacancy conditional on REFORM if CRISIS $=0$ is the non-linear combination: Job vacancy rate + Job vacancy rate*REFORM ( $z$-statistics in parenthesis) 
and the job vacancy rate. The coefficient estimates in this specification are in most cases not statistically significant. However, we can see that the "effect of the job vacancy rate conditional on EPL if CRISIS $=0$ " is negative having a value of -0.528 , while the "effect of the job vacancy rate conditional on EPL if CRISIS $=1$ " is also negative but more sizeable, i.e., -2.029 .

A similar picture emerges if we look the estimates in column 3 of Table 3, the coefficient of the job vacancy rate is positive (0.664) but not statistically significant, the "effect of the job vacancy rate conditional on REFORMS if CRISIS $=0$ " is negative having a value of -1.131 , while the "effect of the job vacancy rate conditional on REFORMS if CRISIS $=1$ " is negative but more sizeable, i.e., -3.210 . However, the coefficient estimates are not particularly significant.

Qualitatively, these findings suggest that it is primarily the effect of the CRISIS that induces a greater responsiveness of the unemployment to vacancy developments relative to a decline in the EPL or the increase in the REFORMS index. Nevertheless, a lower EPL or a higher value of the REFORMS index is in fact reducing the responsiveness of unemployment to vacancy developments. Alternatively put, it is structural reforms at times of economic crisis that induce the greater responsiveness of unemployment to vacancy developments rather than reforms at regular economic times.

As a robustness check in Table 4, we have considered a smaller sample, i.e., 2005 Q4-2015 Q2. Given that vacancy data collection for Greece (and the EU in general) started in early 2004, we drop the first few observations that are likely to be liable to data problems. The findings reported in Table 4 are qualitatively similar to those reported before.

Overall, structural reforms, which increase the flexibility of the labor market, were implemented in a recessionary context, aggravating the unemployment problem. At the same time, there is some preliminary evidence that reforms also improved the efficiency of the matching process. This implies a more pronounced unemployment response at times of increased labor demand when more job vacancies are posted.

Concluding, the results presented in Tables 2-4 correspond to the analysis of Bonthuis et al. (2013) and verify the presence of an inverse relationship between unemployment and vacancies in Greece. This inverse relationship primarily reflects developments after 2008, the time that Greece dipped into recession. The decline in economic activity alongside with a more flexible labor market contributed to an increase in unemployment, i.e., an outward shift in the Beveridge curve. Nevertheless, there is evidence suggesting that the responsiveness of unemployment to vacancy developments has increased on account of structural reforms, which can lead to an improvement of the matching process and a more rapid reduction in the unemployment rate when the job vacancy rate accelerates.

\section{The effect of an economic activity decline on job finding, separation, and vacancy rates: a structural VAR approach}

The analysis in Sections 2 and 3 that examine the evolution of the inflow rate to and outflow rate from unemployment in recent years is unconditional; various factors could have affected these transition rates. In this section, building on the work of Hairault et al. (2015) and using seasonally adjusted (ARIMA X12) data from 2005 Q4 till 2015 Q2, we investigate econometrically the effect on an exogenous shock in economic activity 
Table 4 Beveridge curve estimations (small sample 2005 Q4-2015 Q2)

\begin{tabular}{|c|c|c|c|c|c|c|}
\hline & 1 & 2 & 3 & 4 & 5 & 6 \\
\hline Dependent variable & Unemployment rate & & & & & \\
\hline${\text { Unemployment } \text { rate }_{t-1}}$ & $0.938(37.47)^{* * *}$ & $0.879(30.91)^{* * *}$ & $0.956(43.09)^{* * *}$ & $0.959(42.50)^{* * *}$ & $0.849(29.93)^{* * *}$ & $0.882(22.71)^{* * *}$ \\
\hline Job vacancy rate ${ }_{t}$ & $-3.332(-3.38)^{* * *}$ & $-2.325(-3.68)^{* * *}$ & $-2.497(-3.06)^{* * *}$ & $-1.435(-1.36)$ & $-3.351(-0.93)$ & $1.392(0.54)$ \\
\hline Job vacancy rate $e_{t}^{2}$ & $75.06392 .90^{* * *}$ & $60.712(3.32)^{* * *}$ & $63.647(2.90)^{* * *}$ & $36.123(1.34)$ & $66.531(1.23)$ & $46.855(1.23)$ \\
\hline $\mathrm{CRISIS}_{t}$ & & $0.007(3.28)^{* * *}$ & $0.008(3.23)^{* * *}$ & $0.015(2.44)^{* *}$ & & $0.031(0.82)$ \\
\hline $\mathrm{EPL}_{t}$ & & $-0.021(-2.87)^{* * *}$ & & & $-0.027(-1.01)$ & $-0.011(-0.49)$ \\
\hline Job vacancy rate* ${ }^{*}$ ISIS $t$ & & & & $-0.577(-1.56)$ & & $-2.899(-0.93)$ \\
\hline Job vacancy rate* $E P L_{t}$ & & & & & $0.166(0.08)$ & $-1.122(-0.82)$ \\
\hline CRISIS*EPL ${ }_{t}$ & & & & & & $-0.007(-0.39)$ \\
\hline Job vacancy rate*CRISIS*EPL & & & & & & $0.864(0.70)$ \\
\hline Constant term & $0.041(3.61)^{* * *}$ & $0.089(4.06)$ & $0.026(2.53)$ & $0.016(1.32)$ & $0.118(2.02)^{* *}$ & $0.055(1.09)$ \\
\hline Effect of job vacancy if CRISIS = 1 & & & & $-2.012(-2.36)^{* *}$ & & \\
\hline $\begin{array}{l}\text { Effect of job vacancy conditional } \\
\text { on EPL }\end{array}$ & & & & & $-3.185(-1.87)^{*}$ & \\
\hline $\begin{array}{l}\text { Effect of job vacancy conditional } \\
\text { on EPL if CRISIS }=1\end{array}$ & & & & & & $-1.765(-1.18)$ \\
\hline $\begin{array}{l}\text { Effect of job vacancy conditional } \\
\text { on EPL if CRISIS }=0\end{array}$ & & & & & & $0.270(0.20)$ \\
\hline Obs & 39 & 39 & 39 & 39 & 39 & 39 \\
\hline F-test ( $p$ value) & $F(3,35)=1971.88(0.000)$ & $F(5,33)=2968.04(0.0000)$ & $F(4,34)=2588.66(0.0000)$ & $F(5,33)=3014.69(0.000)$ & $F(5,33)=1606.35(0.0000)$ & $F(9,29)=3776.35(0.000)$ \\
\hline$R^{2}$ & 0.9936 & 0.9962 & 0.9952 & 0.9954 & 0.9950 & 0.9964 \\
\hline
\end{tabular}

Note: Standard errors are corrected for autocorrelation using Newey-West procedure. $* * *, * * *$ denote statistical significance at 1,5 , and $10 \%$ levels, respectively ( $t$-statistics in parenthesis). The effect of job vacancy if
CRISIS $=1$ is the non-linear combination: Job vacancy rate + job vacancy rate*CRISIS ( $z$-statistic in parenthesis). The effect of job vacancy conditional on EPL is the non-linear combination: Job vacancy rate + Job vacancy

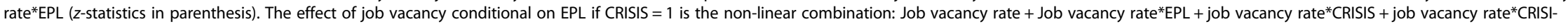
$S^{*} E P L$ ( $z$-statistics in parenthesis). The effect of job vacancy conditional on EPL if CRISIS $=0$ is the non-linear combination: Job vacancy rate + Job vacancy rate*EPL ( $z$-statistics in parenthesis) 
on the transition rate into and out of unemployment and the job vacancy rate. ${ }^{13} \mathrm{We}$ control for the policy changes undertaken in recent years by incorporating the shift dummy variable EAP taking values 1 from 2010 Q2 onwards and zero otherwise; EAP stands for Economic Adjustment Programme. ${ }^{14}$

We consider a structural VAR specification that includes an intercept and where the lag length is set to $2 .{ }^{15}$ The SVAR we estimate is of the form:

$$
X_{t}=A_{1} * X_{t-1}+C_{t}+u_{t}
$$

where $X_{t}=[D y, s, f, v]$ is the vector of endogenous variables, $D y$ stands for real GDP growth rate $\left(D y=y_{t}-y_{t-4}\right), s$ stands for the inflow rate to unemployment, $f$ stands for the outflow rate from unemployment, and $v$ stands for job vacancy rate. $C_{t}$ contains the deterministic terms. In order to conduct an impulse response function analysis, we need to identify the structural shock to $D y$ by imposing on the matrices A and B that determine the mapping from the VAR innovations $u$ to the structural shocks $\varepsilon$ $\left(\mathrm{A} u_{t}=\mathrm{B} \varepsilon_{t}\right)$ the following restrictions (Cholesky decomposition):

$$
\left[\begin{array}{cccc}
1 & 0 & 0 & 0 \\
a_{21} & 1 & 0 & 0 \\
a_{31} & a_{32} & 1 & 0 \\
a_{41} & a_{42} & a_{43} & 1
\end{array}\right] \begin{gathered}
u_{D y t} \\
u_{s t} \\
u_{f t} \\
u_{v t}
\end{gathered}=\left[\begin{array}{cccc}
\beta_{11} & 0 & 0 & 0 \\
0 & \beta_{22} & 0 & 0 \\
0 & 0 & \beta_{33} & 0 \\
0 & 0 & 0 & \beta_{44}
\end{array}\right] \begin{gathered}
\varepsilon_{D y t} \\
\varepsilon_{s t} \\
\varepsilon_{f t} \\
\varepsilon_{v t}
\end{gathered}
$$

These restrictions assume that a percentage change in real GDP growth is not contemporaneously affected by changes in $s, f$, or $v$ and allows us to examine the impulse responses of these three variables following a well-identified exogenous shock on real GDP. Results are presented in Fig. 11a-d. The solid black line represents the response of the variable of interest to the exogenous negative shock on output growth; the two round-dotted black lines are the $68 \%$ confidence bands. ${ }^{16}$ Following a negative output growth shock, the economic downturn lasts for about six quarters and leads to a decline in the job vacancy rate for about nine quarters. The inflow rate to unemployment $(s)$ rises and remains positive for about nine quarters. There is a drop in the outflow rate from unemployment $(f)$ which lasts for about 10 quarters. The increase in the inflow rate and the decline in the outflow rate lead to higher unemployment.

The abovementioned developments imply a downward movement along the Beveridge curve, i.e., as economic conditions deteriorate, job vacancies drop and unemployment rises. Note that the response of the outflow rate is slightly more protracted compared to the one of the inflow rate. Therefore, following a negative economic activity shock, the unemployment rate rises and will continue rising for about one quarter more after the termination of the flows from employment to unemployment.

Building on the impulse responses of the inflow and the outflow rates displayed in Fig. 11a, b and the sample averages of the transition rates $s$ and $f$, we can compute the implied response of the unemployment rate to the negative economic activity shock. The implied unemployment response is calculated as follows:

$$
u_{(t+1)}=u_{(t)}+\left(1-u_{(t)}\right) * s_{(t)}-u_{(t)} * f_{(t)}
$$

where the starting value is $u_{(t)}=13.70 \%$, i.e., it is the steady state unemployment rate $\left(u_{\mathrm{ss}}=s /(s+f)\right)$ that is calculated based on the whole sample averages for $s$ and $f(s=$ $4.34 \%$ and $f=27.31 \%)$. Hence, we assume that the economy is initially at the steady 


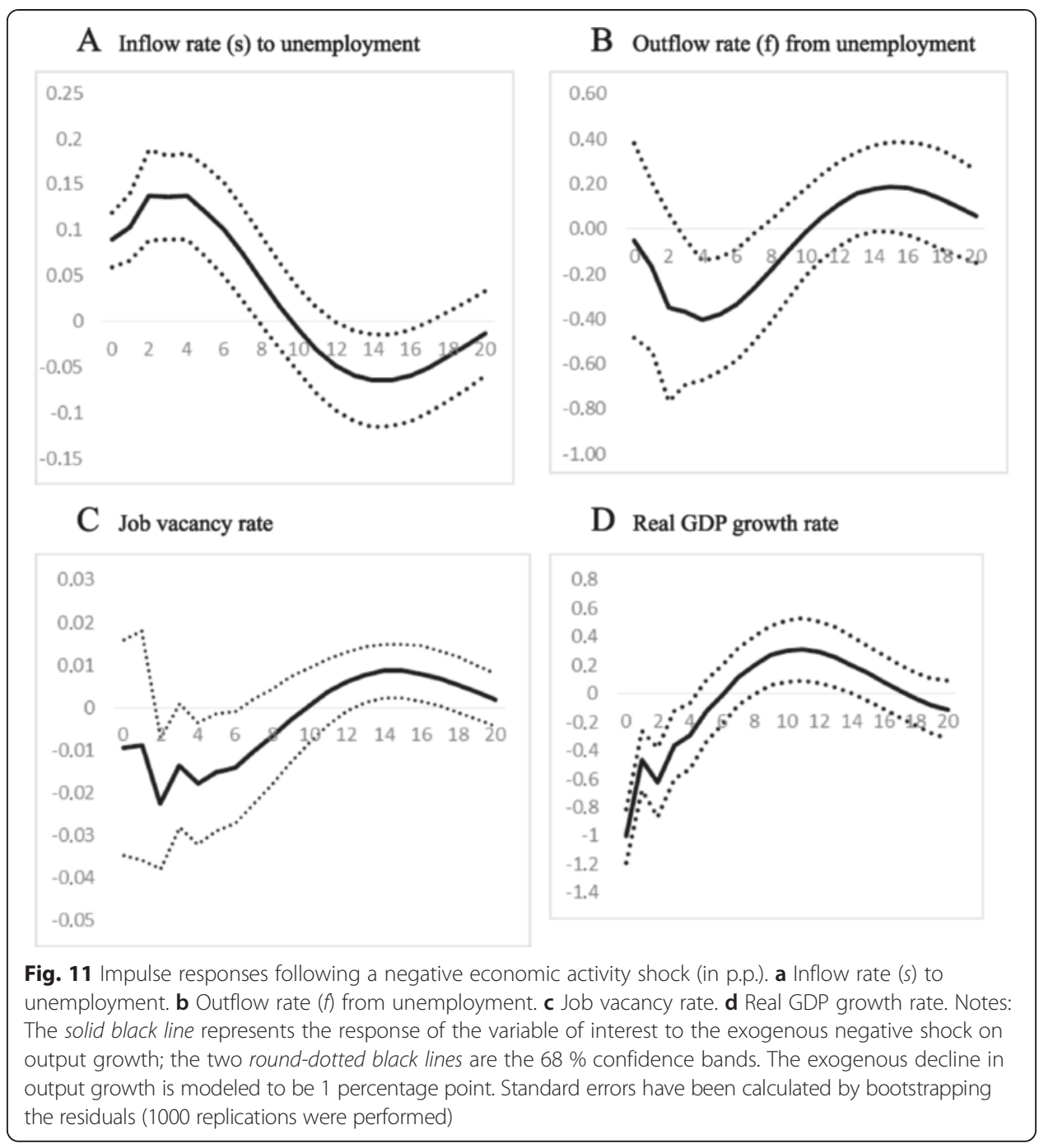

state and moves out of the steady state following the economic activity shock that impacts on the inflow $(s)$ and outflow $(f)$ rates. ${ }^{17}$ The values of $s$ and $f$ that are used in Eq. (11) are continuously updated (starting from the initial values $s=4.34 \%$ and $f=$ $27.31 \%)$ based on the impulse response functions of the inflow $\left(d s_{t} / d y\right)$ and outflow $\left(d f_{t} / d y\right)$ rates (for $t=0,1 \ldots 20$ quarters).

For example, $s_{(t=0)}=4.34 \%+d s_{(t=0)} / d y, s_{(t=1)}=s_{(t=0)}+d s_{(t=1)} / d y, \ldots, s_{(t=20)}=s_{(t=19)}+$ $d s_{(t=20)} / d y$ and $f_{(t=0)}=27.31 \%+d f_{(t=0)} / d y, f_{(t=1)}=f_{(t=0)}+d f_{(t=1)} / d y, \ldots . f_{(t=20)}=f_{(t=19)}+$ $d f_{(t=20)} / d y$. The implied responses of the inflow $(s)$ and outflow $(f)$ rates to an economic activity shock for quarters $t=0,1, \ldots .20$ are depicted in Fig. 12. Iterating Eq. (11) forward, we obtain the implied unemployment rate following an economic activity shock (see Fig. 13).

In order to assess the impact of the inflow rate $(s)$ on the evolution of unemployment rate, we repeat the same exercise as above (we iterate Eq. (11) forward) holding fixed the outflow rate $(f)$ at the initial (sample average) value $f=27.31 \%$. Similarly, to assess the impact of outflow rate (f) on the unemployment rate, we iterate Eq. (11) forward holding fixed the inflow rate $(s)$ at its initial (sample average) value $s=4.34 \%$. 


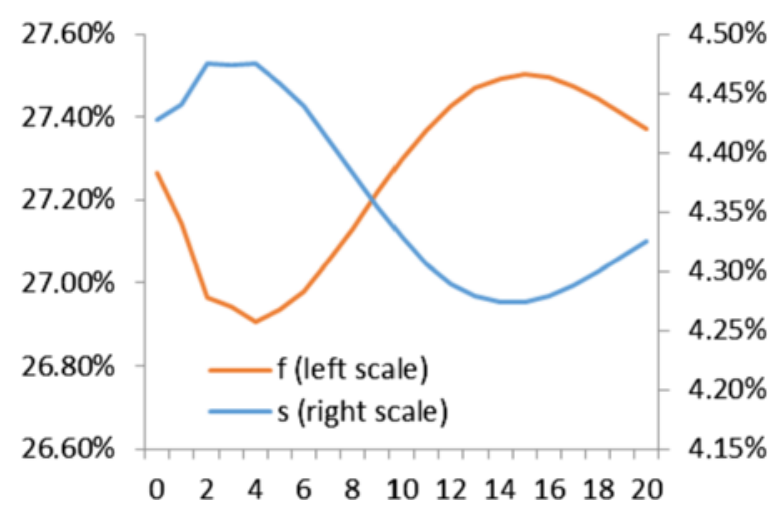

Fig. 12 The implied inflow $(s)$ and outflow $(f)$ rate responses to an economic activity shock

Interestingly, the increase in unemployment is primarily due to the increase in the inflow rate $(s)$ as can be seen from the evolution of the unemployment rate when $f$ is held fixed at its initial value (see Fig. 13). Figure 14a presents the implied unemployment rate response which is positive for about 12 quarters, following an economic activity shock and the contributions of the inflow $(s)$ and outflow $(f)$ rates. ${ }^{18}$

As a robustness check, we repeat the above exercise, but we now consider two additional scenarios for the staring values $s, f$, and $\mathrm{u}$ : (1) we use the average values over the period 2005 Q4-2010 Q1, i.e., $s=2.14 \%$ and $f=28.71 \%$ which imply $u_{\mathrm{ss}}=s /(s+f)=$ $6.95 \%$, and (2) the average values from 2010 Q2 till 2015 Q2, i.e., $s=4.55 \%$ and $f=$ $12.66 \%$, which imply $u_{\mathrm{ss}}=s /(s+f)=26.44 \%$. The findings are reported in Fig. $14 \mathrm{~b}, \mathrm{c}$, respectively. In recent years, the implied response of the unemployment rate is much more pronounced and lasts longer, about 14 quarter vis-à-vis 12 quarters in the first part of the sample (see Fig. 14b, c).

The contribution of the inflow rate $(s)$ is the most important determinant of the unemployment response in the whole sample as well as in the first sub-sample (Fig. 14a, b). However, the contribution of the outflow rate $(f)$ in explaining unemployment fluctuations becomes equally important to that of the inflow rate $(s)$ in most recent years (Fig. 14c). Analogous evidence is reported by Hairault et al. (2015) in the case of France.

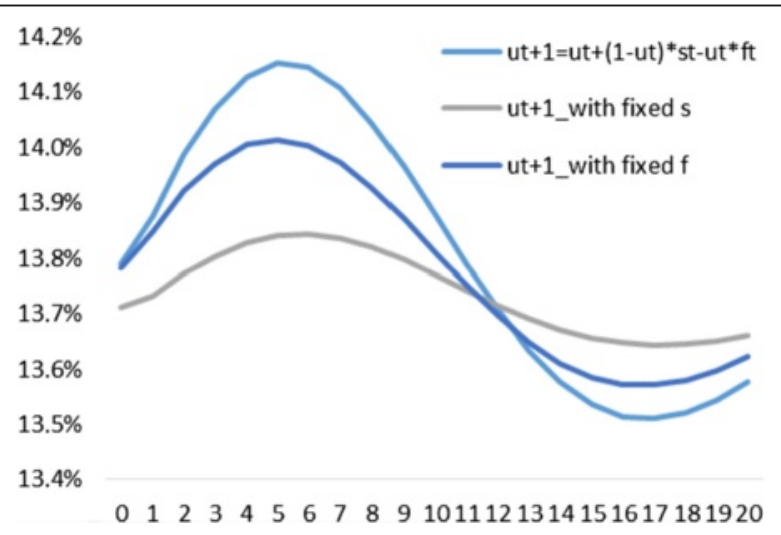

Fig. 13 The implied unemployment rate following and economic activity shock 
Using the implied response of the unemployment rate and the contributions of the inflow and outflow rates (Fig. 14a-c), we construct the covariance contributions of inflow and outflow rates to the variance of the implied unemployment rate. The results are reported in Table 5. The outflow rate accounts for about $47 \%$ of the variability of the unemployment response in the period after 2010, relative to about $16 \%$ in the period before 2010. When considering the whole sample, the inflow rate explains the biggest part (66 \%) of the variability of the unemployment response. These findings resemble to those reported in Table $1 .^{19}$

\section{The role of unemployment persistence}

In the previous section, we examined the inflow and outflow rate responses to a negative economic activity shock, and based on these, we constructed an implied unemployment rate response. However, this implied response might not fully reflect the persistence of actual unemployment rate. Therefore, building on the work of Barnichon and Garda (2015), we build a parsimonious SVAR specification as the one described in Eq. (9) and the specification (10), but we now consider only three variables: the inflow rate $(s)$, the outflow rate $(f)$, and the actual unemployment rate $(u){ }^{20}$

We examine the impact of an exogenous increase on the inflow rate (possibly) driven by adverse business cycle developments. Results are presented in Fig. 15a-c. The solid black line represents the response of the variable of interest to the exogenous shock on inflow rate $(s)$ and the two round-dotted black lines are the $68 \%$ confidence bands. ${ }^{21}$

Following the exogenous shock, the transition rate $s$ remains positive for a period of 10 quarters (Fig. 15a). The decline in the outflow rate is more pronounced but slightly less protracted (it lasts for eight quarters) than the increase in the inflow rate (Fig. 15b). The unemployment rate increases and remains positive for a period of 15 quarters (see Fig. 15c) after the initial inflow rate shock. That is, five to seven quarters more than it would have been implied by the inflow and outflow rate responses. Using the methodology described in the previous section and employing Eq. (11) and the sample averages of $s$ and $f$, we construct the implied response of unemployment rate based on the inflow and outflow rate responses shown in Fig. 15a, b. The implied unemployment rate response is shown with a solid orange line in Fig. 15c. It is more sizeable relative to the actual unemployment response until about the eighth quarter. Thereafter, it declines rapidly and remains positive until the 12th quarter, whereas actual unemployment remains positive for about 15 quarters. This evidence is suggestive of the high persistence in the unemployment dynamics in Greece, which work beyond the estimated responses of the inflow and outflow rates.

\section{A first assessment of the impact of structural reforms on the inflow and the outflow rates from unemployment: a VAR analysis}

The inflow rate to and outflow rate from unemployment are affected both by cyclical and structural factors. In Section 4, we examined the impact of the decline in economic activity on the transition rates into and out of unemployment. In the current section, we investigate the likely impact of the structural reforms that were undertaken in the period under investigation on the inflow $(s)$ and outflow $(f)$ rates. Some of these structural labor market reforms are reflected in the decline of the EPL index (see Fig. 2), which measures the stringency of labor relations. 
A The initial values of $s$ and $f$ are based on whole sample averages, 2005Q4-2015Q2

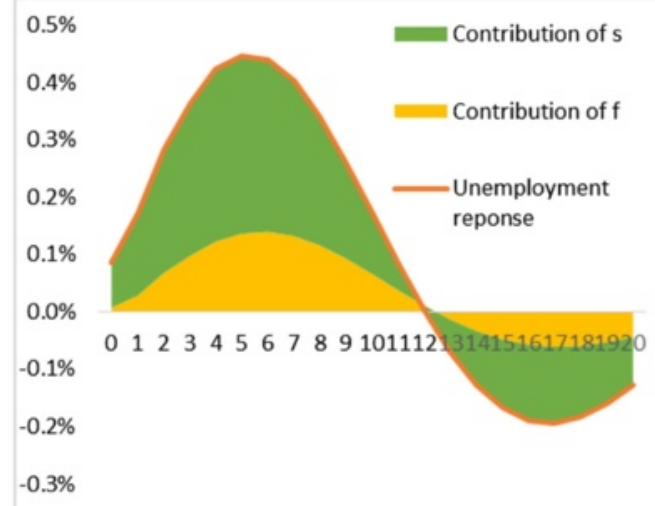

B The initial values of $s$ and $f$ are based on sample averages from 2005Q4 to 2010Q1

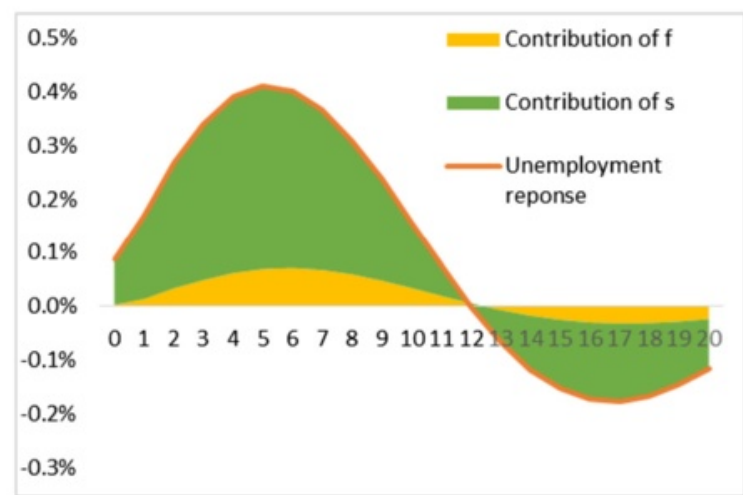

C The initial values of $s$ and $f$ are based on sample averages from 2010Q2 to 2015Q2

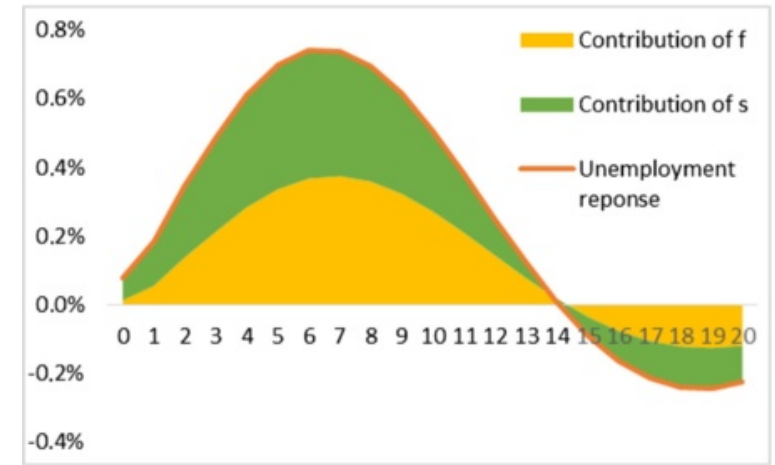

Fig. 14 Implied unemployment rate response and contributions of the inflow (s) and outflow ( $f$ ) rates. a The initial values of $s$ and $f$ are based on whole sample averages, 2005 Q4-2015 Q2. b The initial values of $s$ and $f$ are based on sample averages from 2005 Q4 to 2010 Q1. c The initial values of $s$ and $f$ are based on sample averages from 2010 Q2 to 2015 Q2

Table 5 Covariance contributions of inflow and outflow rates to the unemployment variance (based on the implied unemployment responses of Fig. 14a-C)

\begin{tabular}{llll}
\hline$\beta$ & $2005 \mathrm{Q} 2-2015 \mathrm{Q} 2$ & $2005 \mathrm{Q} 2-2010 \mathrm{Q1}$ & $2010 \mathrm{Q2}-2015 \mathrm{Q} 2$ \\
\hline$\beta_{5}$ & 0.66 & 0.79 & 0.48 \\
$\beta_{f}$ & 0.29 & 0.16 & 0.47 \\
\hline
\end{tabular}




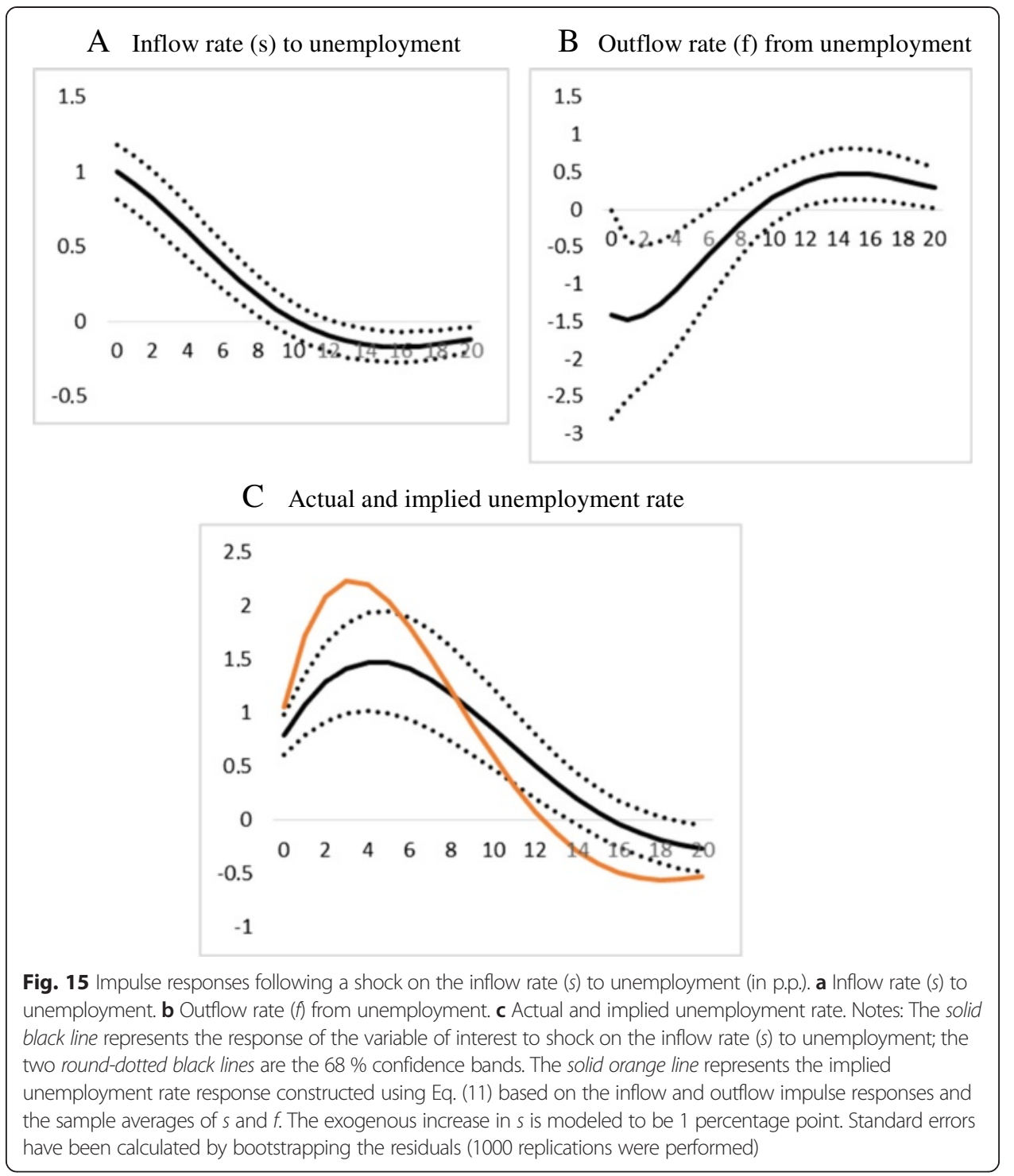

To this end, we estimate a parsimonious three variable VAR with 1 lag: real GDP growth rate $(D y)$, inflow rate $(s)$, outflow rate $(f) .{ }^{22}$ In addition, we include three exogenous variables to control for the effect of structural reforms at various phases of the economic cycle.

These exogenous variables are constructed as follows: The impact of reforms on the inflow $(s)$ and outflow $(f)$ rates can vary depending on the state of the business cycle. Hence, the period under investigation 2003 Q1-2015 Q2 is broken down into three sub-periods: (a) the times of deepening economic recession, i.e., when the annual real GDP growth rate is negative and deteriorates further from one quarter to the other, ${ }^{23}$ (b) the times of gradual recovery (or decelerating recession), i.e., when the annual real GDP growth rate is negative but improves from one quarter to the other, ${ }^{24}$ and (c) the times of economic expansion, i.e., when the real GDP growth rate is positive.

Figure 16 plots the annual real GDP growth rate and the quarterly change of the annual real GDP growth rate. The economy is in a state of deepening recession when both series have negative values. The economy is in a state of gradual recovery (or decelerating recession) when the annual real GDP growth rate is negative but its quarterly change is positive. 


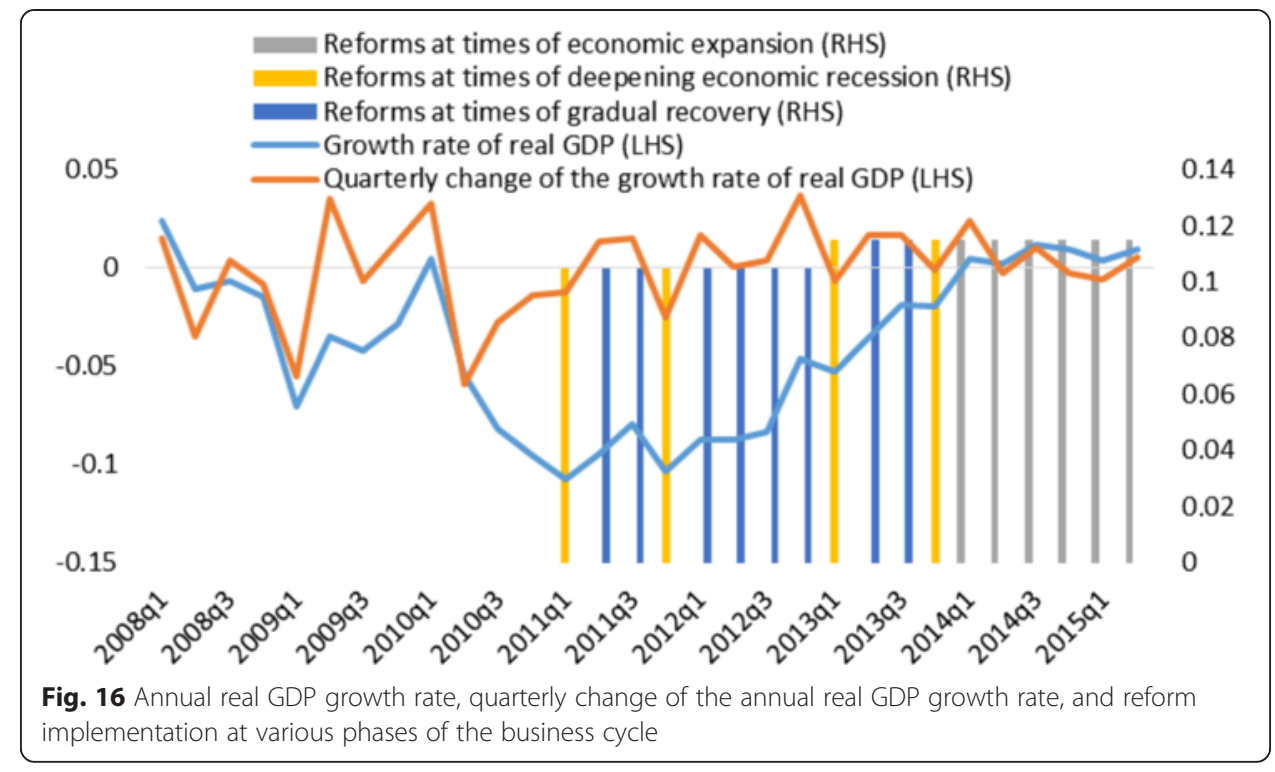

On the basis of the three sub-periods that we identified above, we construct three dummy variables (the times of deepening economic recession, the times of gradual recovery, and the times of economic expansion); each of them takes the value of 1 for the period of reference and 0 otherwise.

Next, we multiply these three dummy variables with the dummy variable REFORMS (which is the inverse of EPL) that was defined in Section 4.1 and obtain three new dummy variables that are incorporated in the VAR described above as exogenous variables. ${ }^{25}$ These three new dummy variables are displayed in Fig. 16 and can be interpreted as progress in structural reforms at distinct phases of the business cycle. Therefore, the value of 0 indicates no reforms (prior to 2011 Q1, there was no change in EPL and hence no progress in reforms), the value of 0.10 stands for the adoption of the first reforms in the period 2011 Q1-2012 Q4, and the value of 0.11 for the additional progress in labor market reforms during the period 2013Q1-2015Q2.

Following Lutkepohl (2005), we employ cumulative dynamic multiplier functions to examine the effect of structural reforms. These functions measure the cumulative effect of a unit change in each of the exogenous variables on the endogenous variables of the VAR. The cumulative dynamic multiplier functions are reported in Figs. 17, 18, and $19 .^{26}$

The structural labor market reforms that are undertaken at times of deepening economic recession increase the inflow rate to unemployment $(s)$, while reducing the outflow rate from unemployment $(f)$ and the real GDP growth rate (see Fig. 17a-c). On the contrary, structural reforms in the labor market at times of decelerating recession or gradual recovery lower the inflow rate $(s)$, while they slightly stimulate the outflow rate $(f)$ and boost output growth (see Fig. 18a-c).

Structural reforms at times of economic expansion have limited effects on the labor market. After a period of 20 quarter, there is a small decline in the inflow rate $(s)$ to unemployment, while the outflow rate $(f)$ to unemployment remains practically unchanged and the real GDP growth rate responds positively (Fig. 19a-c).

Overall, the results suggest that the structural reforms that were undertaken in times of deep economic recession propagated the increase in the inflow rate to unemployment $(s)$, 


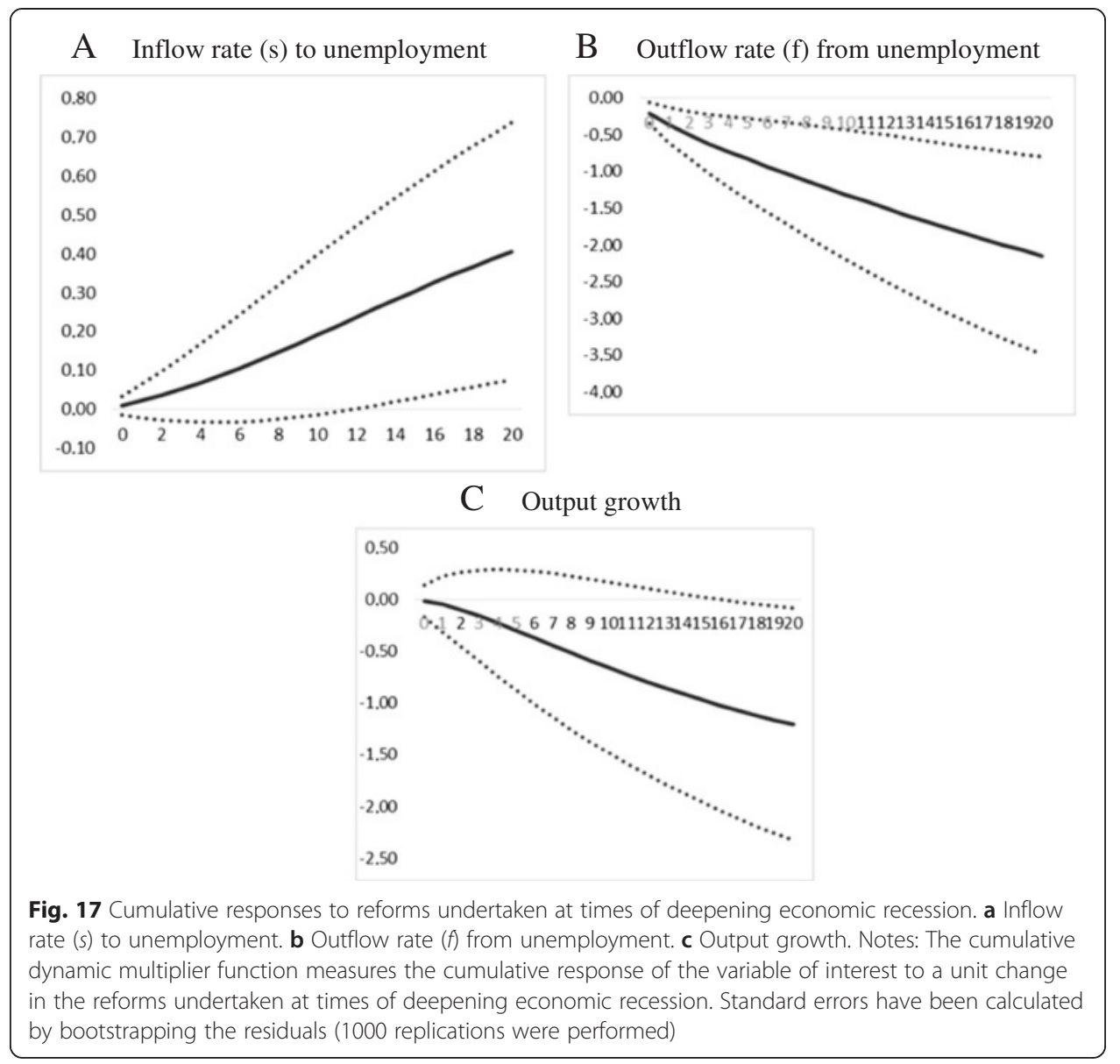

while the structural reforms that were undertaken in times of decelerating economic recession or gradual recovery had a slight positive effect on the outflow rate.

A word of caution is needed here. The abovementioned finding should be considered to be preliminary and constitute a first assessment of the impact of structural reforms that were implemented in recent years. Moreover, it should be kept in mind that the constructed dummy variables do not fully capture the variety of policy interventions that took place in recent years, for example, the reduction of severance payments and the shortening in the notice time for dismissals, the cuts in employers' and employees' social security contributions, the decline in the minimum wage, the changes in the national and sectoral collective agreements and the primacy given to firm level agreements, the pension reform, and the structural reforms in the product and service markets. ${ }^{27}$

\section{Conclusions}

This paper examines the determinants of unemployment dynamics in Greece using Labor Force Survey data from 2000 Q1 to 2015 Q2. Following earlier studies such as Smith (2011) and Petrogolo and Pissarides (2008), we show that the inflow rate to unemployment accounts for the biggest part of unemployment variability over the whole sample period. However, focusing on the most recent crisis years, we found evidence pointing to the opposite direction, i.e., that the outflow rate from unemployment is the most important determinant of the variance of unemployment. 


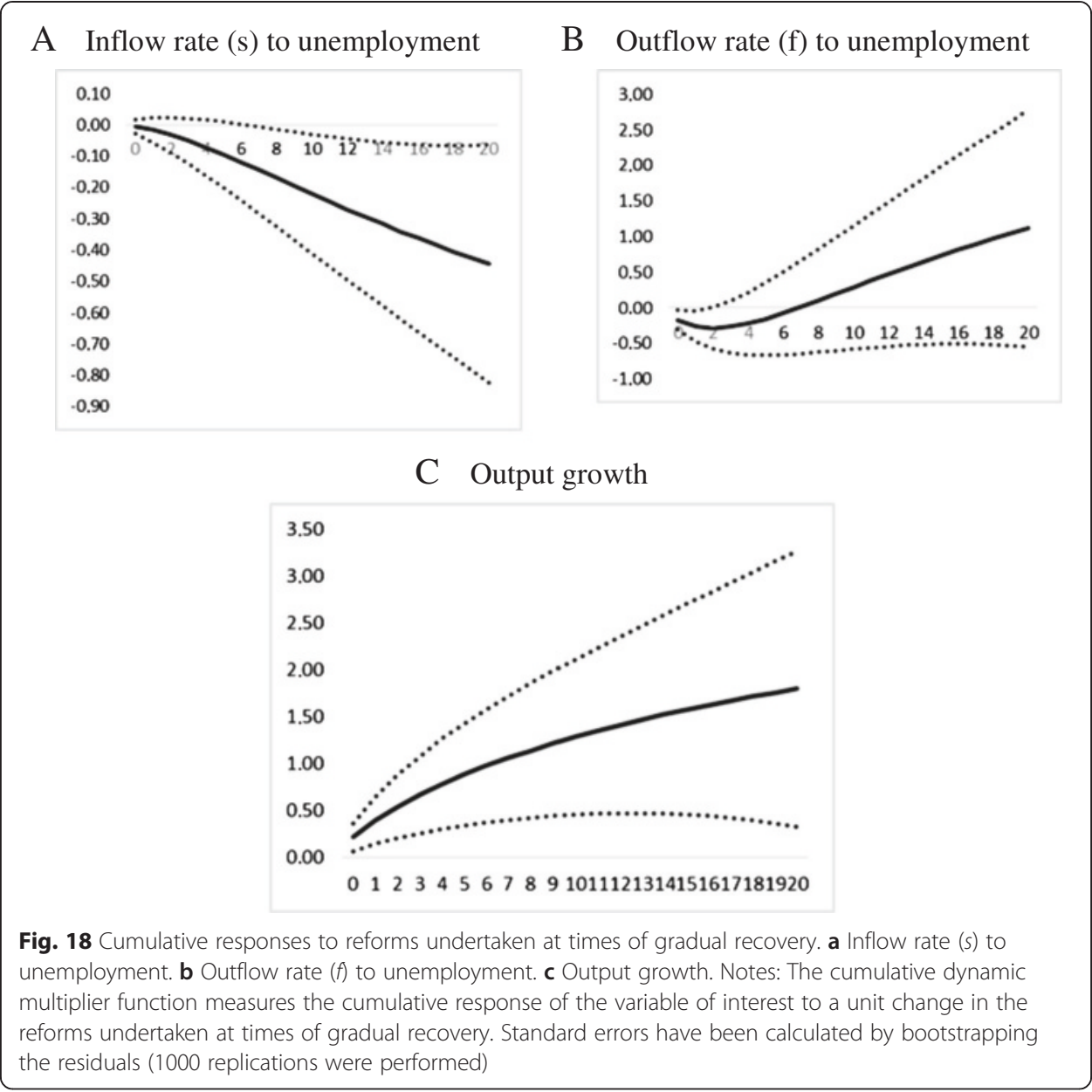

These developments reflect the fact that early in the crisis (the period until the mid of 2012), there was an acceleration of the total inflow rate $(s)$ to unemployment. This is primarily due to the increase in the job separation rate $\left(\lambda_{\mathrm{EU}}\right)$. However, it also reflects a rise in the transition from employment to unemployment via inactivity ( $\mathrm{E} \rightarrow \mathrm{I} \rightarrow \mathrm{U}$ ). These results, which led into rapidly rising unemployment, were driven by the economic recession and the structural reforms (implemented from 2010 onwards) which eased the strictness of labor market regulation. In addition, the reduction in hiring and the posted job vacancies on account of the recession exerted a negative effect on the total outflow rate $(f)$ from unemployment, which in turn contributed further to the rapid rise of the unemployment rate. The increase in the total outflow rate was primarily due to the job finding rate $\left(\lambda_{\mathrm{UE}}\right)$, while the transition from unemployment to employment via inactivity $(\mathrm{U} \rightarrow \mathrm{I} \rightarrow \mathrm{E})$ had a limited effect.

From mid-2012 onwards, uncertainty receded and economic conditions normalized. As a consequence, both inflow and outflow rates improved. In addition, the structural reforms that were initiated since then, i.e., the reduction in social security contributions, the activation of various targeted training and internship labor market programs, the changes in the determination of minimum wages, the primacy given in firm level agreements which could set wages below those in the national collective agreement, etc., facilitated the reduction in labor costs and coupled with the gradually improving 


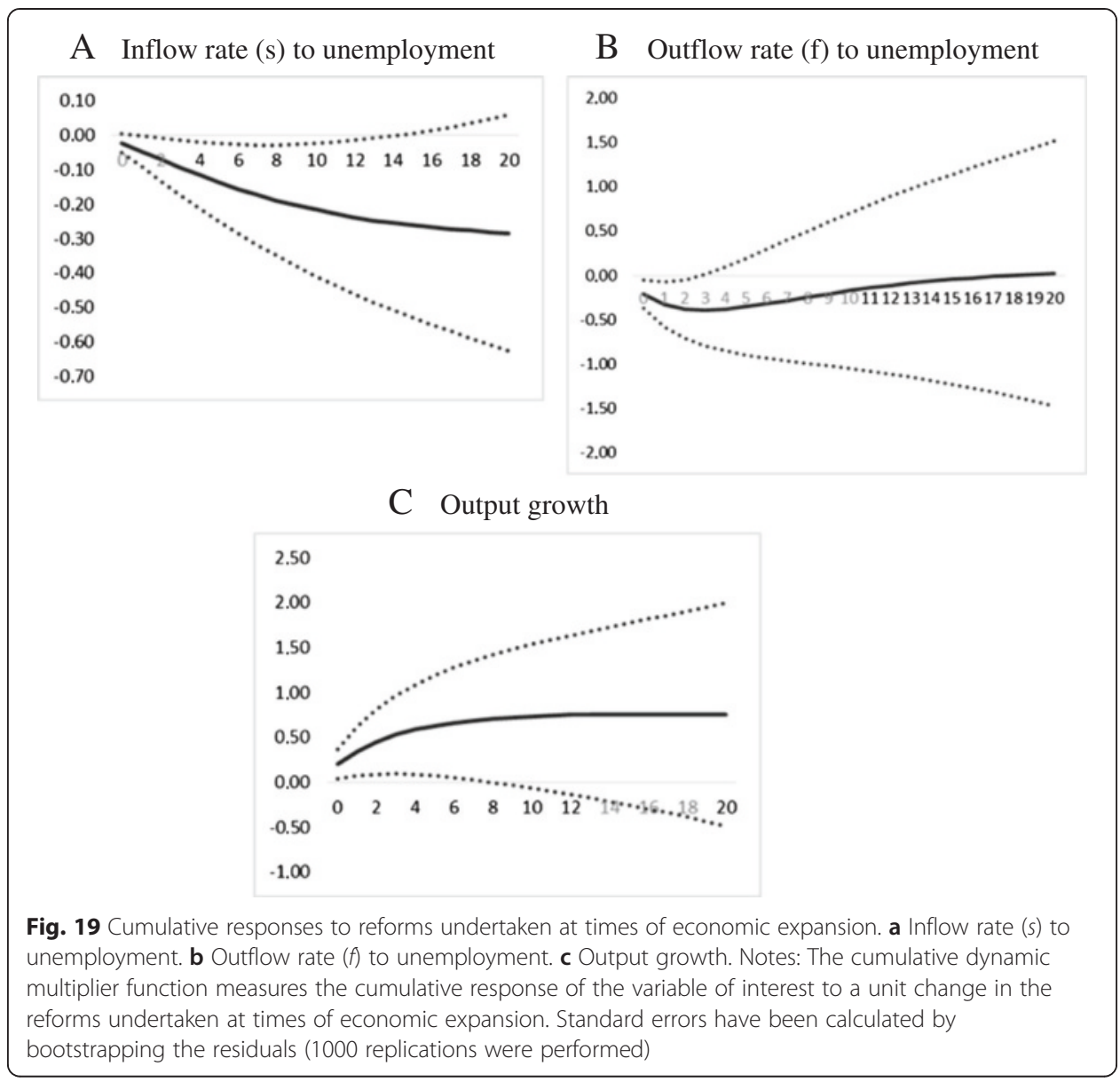

economic conditions contributed to the decline in the inflow rate to and the increase in the outflow rate from unemployment. The latest movements were driven mainly by the decline in the job separation rate $\left(\lambda_{\mathrm{EU}}\right)$ and the increase job finding $\left(\lambda_{\mathrm{UE}}\right)$ rate.

Impulse response functions (based on a SVAR specification) provide econometric evidence for the negative effects of the economic recession on the unemployment dynamics. Cumulative dynamic multiplier functions (from a VAR model) suggest that structural reforms at times of deepening recession can aggravate the unemployment problem by raising the inflow and lowering the outflow rate, while structural reforms undertaken at times of gradual recovery or decelerating recession can be associated with an increase in the outflow and a decline in the inflow rate.

Overall, at times of declining economic activity, the inflow rate to unemployment is the most important determinant of unemployment developments, while at times of economic recovery, it is the outflow rate from unemployment that matters the most. Nevertheless, the SVAR analysis conducted has shown that the negative effects of economic recession on the outflow from unemployment are slightly more protracted compared to those on the inflow rate. This would lead to a delayed response of the unemployment rate at times of economic recovery. Hence, economic recovery without job creation (jobless growth) could result in persistently high unemployment rate.

Building on the analysis of Bonthuis et al. (2013), we verify the presence of an inverse relationship between unemployment and vacancies in Greece. This inverse 
relationship is attributed to economic developments after 2008, the time that Greece dipped into recession. The decline in economic activity alongside with a more flexible labor market contributed to an increase in unemployment, i.e., an outward shift in the Beveridge curve. Nevertheless, there is some evidence suggesting that the responsiveness of unemployment to vacancy developments has increased on account of structural reforms, which can lead to an improvement in the efficiency of the matching process.

Data from 2014 onwards are suggestive of a slight outward shift in the Beveridge curve despite the small decline in unemployment (vis-à-vis its high levels recorded in 2013). The large structural changes and the sectoral reallocation of economic activity on account of the recent crisis have created increased (skill, sectoral, locational) mismatches between unemployed and posted vacancies leading to very high structural unemployment, despite the beneficial effect of labor market reforms on matching efficiency.

Overall, the analysis implies that policy interventions are required on two fronts. First, there is a need to enhance job creation. Second, it is necessary to improve the reemployment chances of the unemployed.

Job creation goes hand-in-hand with new domestic and foreign private investment, which in turn requires a business friendly institutional and tax environment. This could be promoted through the following policy actions: adoption of structural reforms in product and services markers, improved public sector efficiency, stable tax system, and the normalization of the financing and liquidity conditions in the Greek economy, through the loosening and subsequent abolishment of capital controls.

Last but not least, given the structural mismatch between job vacancies and available workers, it is of utmost importance to promote active labor market policies, retraining, and education in order to improve the skills and the re-employment probability of the long-term unemployed.

\section{Endnotes}

${ }^{1}$ The LFS survey is conducted by the Hellenic Statistical Authority (El.Stat.) and concerns about 25,000-30,000 households in each quarter (i.e., about 65,000-80,000 individuals). See Daouli et al. 2015 for information on additional survey characteristics.

${ }^{2}$ The survey data on the recall question suffer from both classification error (the respondents might consider themselves unemployed, while the statistical authority classifies them as employed or inactive) and recall error (the respondents might not be able to correctly recall their last year labor market status). Nevertheless, the correlation between actual unemployment and the implied unemployment based on the recall question is very high $(98.1 \%)$.

${ }^{3}$ The deep recession in the early years of the crisis is also related to the fact that the first Economic Adjustment Programme for Greece paid particular emphasis on the correction of fiscal imbalances. According to the IMF (2015), the primary balance as a percent of GDP improved from $-10.3 \%$ in 2009 to $-3.0 \%$ in 2011 . Subsequently, it still improved but by much less, i.e., it was $-1.4 \%$ in 2012, $1.0 \%$ in 2013, and $0.0 \%$ in 2014. Hence, the biggest part of the fiscal consolidation effort (with devastating effects on output growth) took place in 2010-2011. The same picture emerges if we consider the cyclically adjusted primary balance as a percent of potential GDP, i.e., from $-13.2 \%$ in 2009 it was reduced to $-1.6 \%$ in 2011 and improved further to $1.8 \%$ in 2012, $4.6 \%$ in 2013, and $3.2 \%$ in 2014. 
${ }^{4}$ According to Hairault et al. (2015), the outflow rate to unemployment is the dominant factor to explain the unemployment dynamics in France the period from 2004 to 2010.

${ }^{5}$ The analysis up till now was based on the notion of steady state unemployment. However, as pointed out by Smith (2011) and Elsby et al. (2013), actual unemployment can diverge from steady state unemployment in times of rapidly changing unemployment as is the case in Greece during the recent crisis years. The correlation between the actual and the steady state unemployment is $90.4 \%$ in Greece. Following Smith (2011), we calculated rolling 4-year covariance contributions of the inflow and outflow rates to the variance of actual unemployment. The findings support the conclusions based on the steady state unemployment, i.e., in the early years of the crisis, the inflow rate to unemployment $(s)$ accounted for the biggest part of unemployment movements. However, in the latter years of the crisis, the outflow rate from unemployment $(f)$ had the primary role in explaining the variability of unemployment.

${ }^{6}$ Job vacancy rate $=$ posted vacancies $/$ (posted vacancies + occupied posts).

${ }^{7}$ The high vacancy rates in 2004-2005 relate to the economic expansion associated also with the 2004 Olympic Games. In order to control for seasonality, the values reported for both the job vacancy rate and the unemployment rate are averages over four quarters, i.e., the observation for 2004 Q4 is the average of 2004 Q1-2004 Q4.

${ }^{8}$ The data were seasonally adjusted by means of ARIMA X12-program.

${ }^{9}$ OLS regressions with standard errors corrected with the Newey-West procedure.

${ }^{10}$ For stability, the coefficient of the lagged dependent variable should be strictly less than unity.

${ }^{11}$ The OECD EPL index runs until 2013. The dummy variable REFORM takes the value of 3 from 2013 Q1 to 2015 Q2 assuming that the EPL index will remain at its 2013 level for the coming years (from 2014 up until mid-2015). This assumption reflects the fact that no further reforms have been implemented regarding the conditions for hiring and firing as well as that none of the previous reforms was undone in recent years (Organization for Economic Cooperation and Development OECD 2016).

${ }^{12}$ The same picture emerges from Figs. 7-10; one should just reverse the $Y$ and $X$ axis, placing the unemployment rate on the $Y$ axis and the job vacancy rate on the $X$ axis.

${ }^{13}$ As discussed before, given that the job vacancy data collection started in early 2004, the first observations might be affected by various errors-to address these concerns, we rely on a slightly smaller sample 2005 Q4-2015 Q2.

${ }^{14}$ The EU-IMF financed Economic Adjustment Programme for Greece was initiated in May 2010 (see Tagkalakis, 2013).

${ }^{15}$ The lag length was chosen based on the information provided by relevant laglength selection criteria (LR test and Akaike information criterion), LM test on no autocorrelation, and the need to work with a parsimonious specification in view of the small sample size (see Tables A.1-A.2). The VAR satisfies the stability conditions (Table A.3).

${ }^{16}$ The exogenous decline in output growth is modeled to be one percentage point. Standard errors have been calculated by bootstrapping the residuals (1000 replications were performed). 
${ }^{17}$ I would like to thank one of the referees for making this useful suggestion.

${ }^{18}$ The implied responses in Fig. 14a are the unemployment responses in Fig. 13 after subtracting the initial starting value $u=13.70 \%$.

${ }^{19}$ We have repeated the above exercise, i.e., we estimated a 2-lag SVAR after replacing the yearly GDP growth rate with quarterly GDP growth rate to avoid potential autocorrelation issues. The impulse responses are shown in Figure A1 (see Appendix), the implied unemployment responses for the three scenarios regarding $s$ and $f$ are shown in Figure A2 (see Appendix), and the constructed covariance contributions are shown in Table A4 (see Appendix). Overall, the results are qualitatively similar; the only noticeable difference is that the implied unemployment responses are more sizeable and protracted.

${ }^{20}$ We consider a one lag SVAR which also includes the EAP dummy and a constant term. The sample size is 2003 Q1-2015 Q2 (in the previous section, we had also incorporated job vacancies-that is why we started in 2005 Q4). The lag length was chosen based on the information provided by relevant lag-length criteria, LM test on no autocorrelation, and the need to work with a parsimonious specification in view of the small sample size (see Appendix, Tables A.5-A.7).

${ }^{21}$ The exogenous increase in $s$ is modeled to be one percentage point. Standard errors have been calculated by bootstrapping the residuals (1000 replications were performed).

${ }^{22}$ The lag length was chosen based on the information provided by relevant laglength criteria, LM test on no autocorrelation, and the need to work with a parsimonious specification in view of the small sample size (see Appendix, Tables A.7-A.10).

${ }^{23}$ In more detail: $D y_{t}=y_{t}-y_{t-4}<0$ and $D y_{t}-D y_{t-1}=\left(y_{t}-y_{t-4}\right)-\left(y_{t-1}-y_{t-5}\right)<0$.

${ }^{24}$ In more detail: $D y_{t}=y_{t}-y_{t-4}<0$ and $D y_{t}-D y_{t-1}=\left(y_{t}-y_{t-4}\right)-\left(y_{t-1}-y_{t-5}\right)>0$.

${ }^{25}$ As can be seen in Fig. 2, reforms that reduced the EPL index were initiated only in the period from 2011 Q1 onwards. Before that time, the EPL index was not changed at all. Given that we want to focus only on reform implementation, i.e., the change in the EPL index, we subtract from the constructed series REFORMS (=1/EPL) its value that corresponds to the pre-2011 Q1 period. Hence, the variable employed actually shows the incremental improvement in reform implementation (or the incremental change in EPL index). During non-reform periods, the variable REFORMS will take the value of 0 .

${ }^{26}$ Standard errors have been calculated by bootstrapping the residuals (1000 replications were performed).

${ }^{27}$ On account of product market reforms, the product market regulation (PMR) index of the OECD for Greece declined from a value of 2.21 in 2008 to 1.74 in 2013 (Organization for Economic Cooperation and Development OECD 2016).

\section{Appendix}

Table 6 Lag selection criteria

\begin{tabular}{lllllllll}
\hline lag & $L L$ & $L R$ & $d f$ & $p$ & FPE & AIC & HQIC & SBIC \\
0 & 490.725 & & & & $2.6 e-16$ & -24.55 & -24.3664 & -24.0382 \\
1 & 573.496 & 165.54 & 16 & 0.000 & $8.5 e-18$ & -27.9742 & $-27.5456^{*}$ & $-26.7798^{*}$ \\
2 & 592.331 & $37.671^{*}$ & 16 & 0.002 & $7.7 e-18^{*}$ & $-28.1196^{*}$ & -27.4462 & -26.2427 \\
3 & 600.304 & 15.945 & 16 & 0.457 & $1.3 e-17$ & -27.7079 & -26.7896 & -25.1486 \\
\hline
\end{tabular}

"Note: The chosen specification is the one with 2 lags (based on LR, FPE, AIC - test value indicated in italics). A "*" points to the lag selected by each test" 
Table 7 Lagrange multiplier test

\begin{tabular}{llll}
\hline lag & chi $^{2}$ & $d f$ & ${\text { Prob }>\text { chi }^{2}}$ \\
1 & 23.6374 & 16 & 0.09773 \\
2 & 13.4864 & 16 & 0.63692 \\
Ho : no autocorrelation at lag order & & \\
\hline
\end{tabular}

Table 8 Eigenvalue stability condition

\begin{tabular}{ll}
\hline Eigenvalue & Modulus \\
$0.8977185+0.2552436 i$ & 0.933299 \\
$0.8977185-0.2552436 i$ & 0.933299 \\
$0.5252072+0.2808765 i$ & 0.595596 \\
$0.5252072-0.2808765 i$ & 0.595596 \\
-0.5355586 & 0.535559 \\
-0.3401789 & 0.340179 \\
$-0.051685+0.3233111 i$ & 0.327416 \\
$-0.051685-0.3233111 i$ & 0.327416 \\
\hline
\end{tabular}

All the eigenvalues lie inside the unit circle. VAR satisfies stability conditions

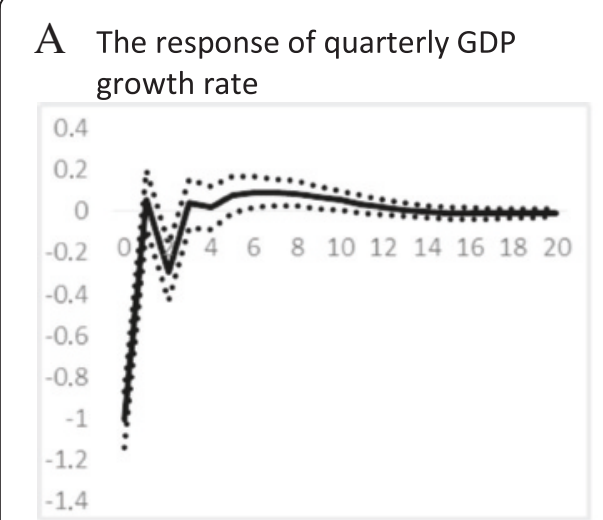

C The response of outflow rate (f) from unemployment

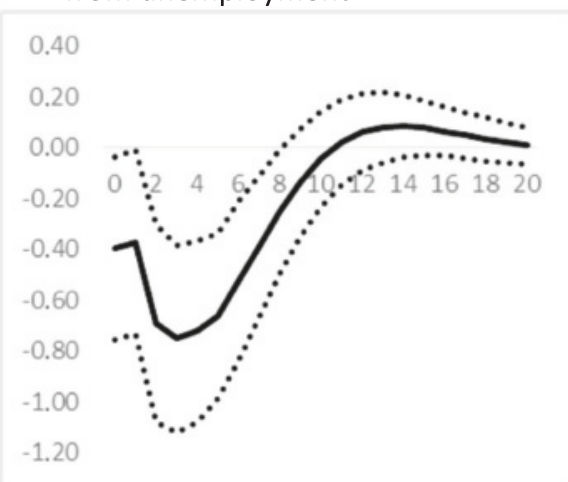

B The response of inflow rate (s) to unemployment

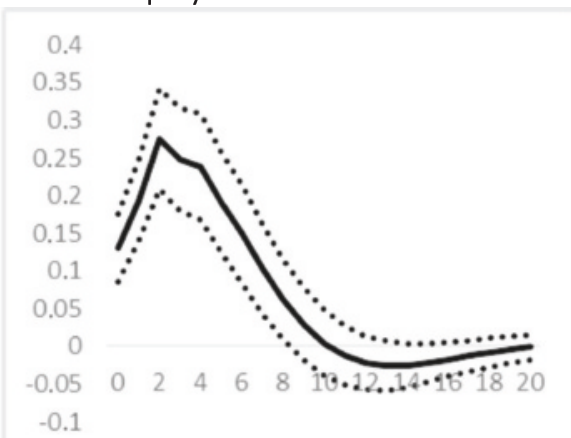

D The response of the job vacancy rate

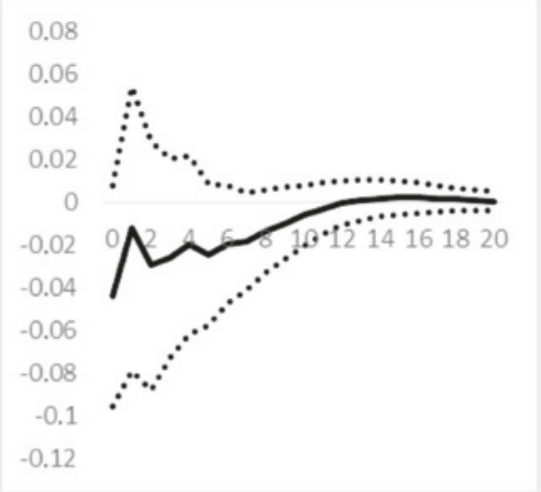

Fig. 20 Impulse responses to a negative economic activity shock (in p.p.). a The response of quarterly GDP growth rate. $\mathbf{b}$ The response of inflow rate $(s)$ to unemployment. $\mathbf{c}$ The response of outflow rate $(f)$ from unemployment. $\mathbf{d}$ The response of the job vacancy rate. Notes: The solid black line represents the response of the variable of interest to the exogenous negative shock on quarterly output growth; the two round-dotted black lines are the $68 \%$ confidence bands. The exogenous decline in quarterly output growth is modeled to be 1 percentage point (p.p). Standard errors have been calculated by bootstrapping the residuals (1000 replications were performed) 
Table 9 Covariance contributions of inflow and outflow rates to the unemployment variance (based on the implied unemployment responses of Fig. 21)

\begin{tabular}{llll}
\hline$\beta$ & $2005 \mathrm{Q} 2-2015 \mathrm{Q} 2$ & $2005 \mathrm{Q} 2-2010 \mathrm{Q1}$ & 2010 Q2-2015 Q2 \\
\hline$\beta_{s}$ & 0.64 & 0.77 & 0.45 \\
$\beta_{f}$ & 0.30 & 0.17 & 0.49 \\
\hline
\end{tabular}

Table 10 Lag selection criteria (unemployment persistence SVAR)

\begin{tabular}{lllllllll}
\hline lag & $L L$ & $L R$ & $d f$ & $p$ & FPE & AIC & HQIC & SBIC \\
0 & 410.136 & & & & $2.2 \mathrm{e}-11$ & -16.0454 & -159.144 & -15.7013 \\
1 & 575.15 & $330.03^{*}$ & 9 & 0.000 & $4.2 \mathrm{e}-14^{*}$ & $-22.286^{*}$ & $-22.0239^{*}$ & $-21.5977^{*}$ \\
2 & 579.368 & 84.373 & 9 & 0.491 & $5.2 \mathrm{e}-14$ & -22.0947 & -21.7016 & -21.0622 \\
3 & 581.008 & 32.793 & 9 & 0.952 & $7.0 \mathrm{e}-14$ & -21.8003 & -21.2761 & -20.4237 \\
4 & 583.498 & 49.801 & 9 & 0.836 & $9.4 \mathrm{e}-14$ & -21.5399 & -20.8846 & -19.8191 \\
\hline
\end{tabular}

"Note: The chosen specification is the one with 1 lags, see LR, FPE, AIC, HQIC, SBIC test (a "*" points to the lag selected by each test)"

Table 11 Lagrange multiplier test (unemployment persistence SVAR)

\begin{tabular}{llll}
\hline $\operatorname{lag}$ & chi $^{2}$ & df & Prob > chi \\
1 & 80.945 & 9 & 0.52465 \\
2 & 27.440 & 9 & 0.97359 \\
\hline
\end{tabular}

Table 12 Eigenvalue stability condition (unemployment persistence SVAR)

\begin{tabular}{ll}
\hline Eigenvalue & Modulus \\
$0.8900651+0.1704689 i$ & 0.906243 \\
$0.8900651-0.1704689 i$ & 0.906243 \\
0.7216574 & 0.721657
\end{tabular}

All the eigenvalues lie inside the unit circle. VAR satisfies stability conditions

Table 13 Lag selection criteria (structural reforms VAR)

\begin{tabular}{lllllllll}
\hline lag & $\mathrm{LL}$ & $\mathrm{LR}$ & $\mathrm{df}$ & $\mathrm{p}$ & $\mathrm{FPE}$ & $\mathrm{AIC}$ & $\mathrm{HQIC}$ & $\mathrm{SBIC}$ \\
0 & 385.612 & & & & $6.5 \mathrm{e}-11$ & -14.9445 & -14.7697 & -14.4856 \\
1 & 479.323 & 187.42 & 9 & 0.000 & $2.2 \mathrm{e}-12^{*}$ & $-18.3329^{*}$ & $-18.0271^{*}$ & $-17.5299^{*}$ \\
2 & 485.01 & 11.375 & 9 & 0.251 & $2.5 \mathrm{e}-12$ & -18.2004 & -17.7635 & -17.0532 \\
3 & 488.842 & 76.631 & 9 & 0.568 & $3.2 \mathrm{e}-12$ & -17.9937 & -17.4257 & -16.5023 \\
4 & 499.786 & $21.889^{*}$ & 9 & 0.009 & $3.1 \mathrm{e}-12$ & -18.0714 & -17.3725 & -16.2359 \\
\hline
\end{tabular}

"Note: The chosen specification is the one with 1 lags, see LR, FPE, AIC, HQIC, SBIC test (a "*" points to the lag selected by each test)"

Table 14 Lagrange multiplier test (structural reforms VAR)

\begin{tabular}{llll}
\hline lag & chi $^{2}$ & $d f$ & ${\text { Prob }>\text { chi }^{2}}^{2}$ \\
1 & 96.152 & 9 & 0.38253 \\
2 & 71.813 & 9 & 0.61825 \\
\hline
\end{tabular}

Ho : no autocorrelation at lag order

Table 15 Eigenvalue stability condition (structural reforms VAR)

\begin{tabular}{ll}
\hline Eigenvalue & Modulus \\
$0.9293062+0.03336861 i$ & 0.929905 \\
$0.9293062-0.03336861 i$ & 0.929905 \\
0.6784126 & 0.678413
\end{tabular}

All the eigenvalues lie inside the unit circle. VAR satisfies stability conditions 
A The initial values of $s$ and $f$ are based on whole sample averages, 2005Q4-2015Q2

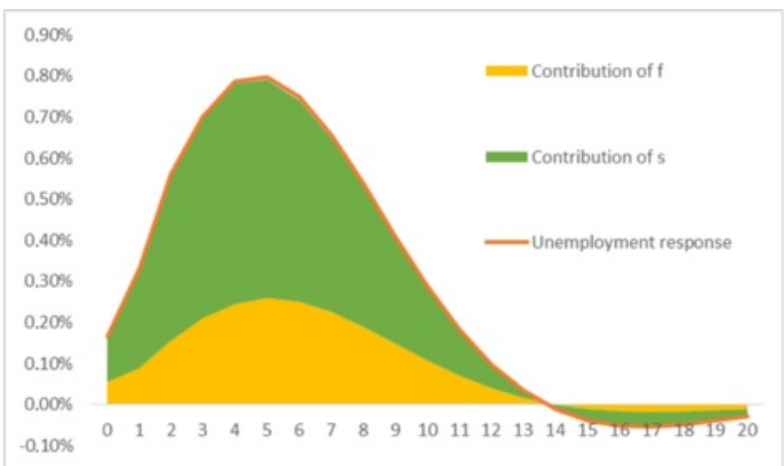

B The initial values of $s$ and $f$ are based on sample averages from $2005 Q 4-2010 Q 1$

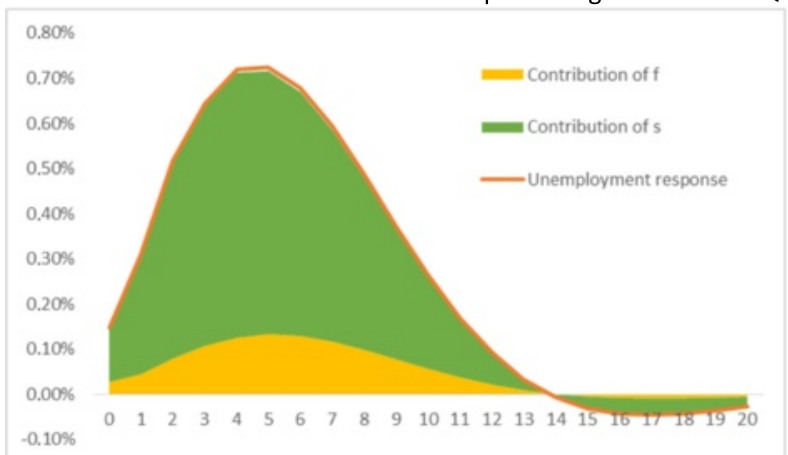

C The initial values of $s$ and $f$ are based on sample averages from 2010Q2-2015Q2

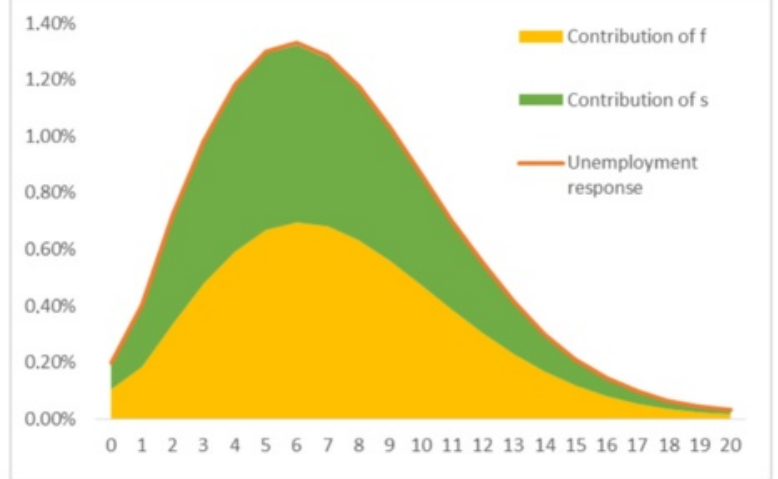

Fig. 21 Implied unemployment rate response and contributions of the inflow $(s)$ and outflow $(f)$ rates. a The initial values of $s$ and $f$ are based on whole sample averages, 2005 Q4-2015 Q2. b The initial values of $s$ and $f$ are based on sample averages from 2005 Q4-2010 Q1. c The initial values of $s$ and $f$ are based on sample averages from 2010 Q2-2015 Q2

\section{Competing interests}

The IZA Journal of European Labor Studies is committed to the IZA Guiding Principles of Research Integrity. The author declares that he has observed these principles.

\section{Acknowledgements}

I would like to thank the Editor Sara de la Rica and the reviewers of IZA Journal of European Labor Studies for their very helpful comments. I also thank Fragiskos Archontakis, Heather Gibson, Franciscos Koutentakis, Dimitris Malliaropulos, Manolis Mamatzakis, and Costas Milas for their useful comments in the earlier versions of the paper. Special thanks to Stelios Zachariou of EL.STAT. for providing the Labor Force Survey data. The views of the paper are my own and do not necessarily reflect those of the Bank of Greece. All remaining errors are mine. Responsible editor: Sara de la Rica 
Received: 8 December 2015 Accepted: 21 April 2016

Published online: 12 July 2016

\section{References}

Bank of Greece (2015) Monetary policy-interim report, special issue IV.1: the determinants of unemployment dynamics and the Beveridge curve in Greece., pp 74-80, in Greek

Barnichon R, Garda P (2015) Forecasting unemployment across countries: the ins and outs. CEPR discussion paper series, No. 10910

Bonthuis B, Jarvis V, Vanhala J (2013) What's going on behind the euro area Beveridge curve(s)? ECB working paper, no.1586

Daouli J, Demoussis M, Giannakopoulos N, Lambropoulou N (2015) The ins and outs of Greek unemployment in the current Greek economic crisis. S-East Eur J Econ 2:177-196

Elsby MWL, Michaels R, Solon G (2009) The ins and outs of cyclical unemployment. Am Econ J: Macroec 1(1):84-110 Elsby MWL, Hobijn B, Sahin A (2013) Unemployment dynamics in the OECD. Rev Econ Stat 95(2):530-548

European Commission (2015) Quarterly report on the euro area, vol 14. no.4 institutional paper 016, January 2016. Box II.1 relative price adjustment in EMU—an empirical assessment., pp 27-32

European Commission (2016) European economic forecast, winter, institutional paper 020, February 2016

Fujita S, Ramey G (2009) The cyclicality of separation and job finding rates. Int Econ Rev 50(2):415-430

Hairault JO, Le Barbanchon T, Sopraseuth T (2015) The cyclicality of the separation and job finding rates in France. Eur Econ Rev 76:60-84

Hall RE (2005) Employment efficiency and sticky wages: evidence from flows in the labour market. Rev Econ Stat 297(3):397-407

IMF (2015) Fiscal monitor. October. IMF, Washington

Lutkepohl H (2005) New introduction to multiple time series analysis. Springer, New York

Organization for Economic Cooperation and Development (OECD) (2016) Economic surveys. OECD, Greece. Paris Petrogolo B, Pissarides C (2008) The ins and outs of European unemployment. Am Econ Rev 98(2):256-262

Shimer R (2005) The cyclical behavior of equilibrium unemployment and vacancies. Am Econ Rev 95(1):25-49

Shimer R (2012) Reassessing the ins and outs of unemployment. Rev Econ Dyn 15:127-148

Smith J (2011) The ins and outs of UK unemployment. Econ J 121:402-444

Tagkalakis A (2013) The unemployment effects of fiscal policy: recent evidence from Greece. IZA J Eur Lab Stud 2:11

\section{Submit your manuscript to a SpringerOpen ${ }^{\circ}$ journal and benefit from:}

- Convenient online submission

Rigorous peer review

- Immediate publication on acceptance

- Open access: articles freely available online

- High visibility within the field

- Retaining the copyright to your article 